\title{
Molecular Classification of Exudates from the Monocots, Magnoliids, and Basal Eudicots ${ }^{1}$
}

\author{
Joseph B. Lambert ${ }^{2}$, Connor L. Johnson' ${ }^{2}$, Allison J. Levy ${ }^{2}$, \\ Jorge A. Santiago-Blay ${ }^{3}$, and Yuyang $\mathrm{Wu}^{4}$
}

\begin{abstract}
This study provides molecular classifications by nuclear magnetic resonance spectroscopy for exudates from the monocots, the magnoliids, the basal eudicots, and core eudicots other than rosids and asterids. The monocots and magnoliids diverged prior to the eudicots from the angiosperm lineage. Our analyses include 78 samples from 10 orders and 14 families. The magnoliid exudates have diverse molecular origins. Within the monocots, the genus Aloe of the Xanthorrhoeaceae provides a conserved phenolic exudate that is different from the class called kinos and is proposed as a new class. Within the commelinid clade of the monocots, exudates of the Arecales (palms) are primarily gums, whereas those of the Poales (grasses) are diverse. A single sample from the Ranuncales within the basal eudicots is phenolic. The core eudicots (other than rosids and asterids) include the Saxifragles, from which the storax exudate of the genus Liquidambar of the Altingaceae is a terpenoid resin, not a phenolic material as previously reported. Also from the core eudicots, exudates from the Cactaceae of the Caryophyllales primarily are gums.
\end{abstract}

Key Words: aloes, eudicots, gums, gum resins, kinos, magnoliids, monocots, NMR, phenolics, plant exudates, resins

\section{Introduction}

Plant exudates comprise a chemically diverse group of materials that are released usually in response to trauma due to damage, disease, or drought. They appear most obviously on the trunk and branches of trees and shrubs but also may appear on leaves, stems, and roots, as well as well as with other types of plants (Lambert et al. 2013a). Although sap and nectar formally are included, we generally restrict our investigations to exudates that solidify to a robustly stable material, usually in hours to days. Such stable solids may be stored safely for years and may be studied in either the solid state or in solution. Solid plant exudates have played an important role in human culture for millennia (Rodríguez et al. 2013), including as incense, jewelry, medicinal products, food,

\footnotetext{
${ }^{1}$ Submitted on June 11, 2015. Accepted on July 3, 2015. Last revisions received on July 23, 2015.

${ }^{2}$ Department of Chemistry, Trinity University, One Trinity Place, San Antonio, Texas 78212-1200 USA. E-mail: jlambert@northwestern.edu

${ }^{3}$ Department of Paleobiology, National Museum of Natural History, Washington, District of Columbia 20560 USA. E-mail: blay@ si.edu

${ }^{4}$ Department of Chemistry, Northwestern University, 2145 Sheridan Road, Evanston, Illinois, 60208-3113 USA. E-mail: y-wu1@northwestern.edu
}

DOI: 10.9784/LEB3(2)Lambert.01

Electronically available on July 27, 2015. Mailed on July 25, 2015. 
cosmetics, adhesives, violin rosin, solder, wine additives, and many others (Langenheim 2003, Nussinovitch 2010).

Molecular classification of plant exudates. We adhere to a strictly molecular classification of plant exudates. Unfortunately, common usage has led to many imprecise terms. Although we cannot avoid these terms in nontechnical contexts, we confine their definitions for the purpose of this study to ones that conform to molecular characteristics. Thus gums comprise a major molecular class of exudates, but the word is applied widely in many different contexts. The first dictionary definition of the third meaning of the word "gum," however, supports a molecular classification: "any of numerous colloidal polysaccharide substances of plant origin that are gelatinous when moist but harden on drying" (Merriam-Webster 2003). The key elements of this definition are that the molecular identity of the material is polysaccharide (high molecular weight carbohydrates or sugars) and that the materials solidify after initial exudation. Further entries considerably broaden this definition in popular senses, to include exudates specifically from eucalyptus trees and to exudates in general, but we retain the quoted definition sensu stricto. Gums have been reviewed thoroughly in the monograph by Nussinovitch (2010).

Possibly the largest class of exudates comprises the resins, which were reviewed in great detail in the monograph by Langenheim (2003). MerriamWebster (2003) provides a very general, non-molecular definition: "any of various solid or semisolid amorphous fusible flammable organic substances ... that are soluble in organic solvents (as ether) but not in water." The primary distinction from other types of exudates made here is the condition of solubility. Whereas fresh gums generally are soluble in water and insoluble in organic solvents, resins have the reverse properties. Unfortunately, numerous molecular classes fulfill this simple criterion. We use the term "resin" exclusively to describe exudates that are primarily hydrocarbon in composition, with almost the entire structure based on the chemical class known as terpenes. Langenheim (2003) employs the term "resin" loosely and includes exudates that are based on polyphenolic structures. Phenols are compounds whose core structure is the benzene molecule with a hydroxy (HO-) substituent, or its derivatives. They are chemically very distant from the hydrocarbon structure of terpenes, although they often are soluble in organic solvents. Polymers constructed from the condensation of alternating units of phenol and an aldehyde such as formaldehyde were named "phenolic resins" by chemists who had no interest in or knowledge of plant exudates, so that the term "resins" is used widely for this class of materials. In the context of exudates, however, we avoid such a term. No known phenolic exudates are condensation polymers of phenol and formaldehyde, so the term "phenolic resin" as originally coined is incorrect under any circumstance. For such materials, we prefer the simple molecular term "phenolic." 
Many plants exude materials that contain both gums and resins and have long been known as "gum resins." Merriam-Webster (2003) appropriately provides the following definition of this term: "a product consisting essentially of a mixture of gum and resin."

Eucalyptus trees exude a characteristic material, known as "gum" in Australia, which is phenolic in structure, although not a phenolic resin in the sense of polymer technology. The term "kino" has been used to describe such materials in Africa, India, and Australia, so we have adopted this term for eucalypt and related exudates (Lambert et al. 2007b), as a specific and well characterized subclass of phenolics. The term is not present in the MerriamWebster dictionary, but the more comprehensive Oxford English Dictionary (2009) provides the following definition: "a substance resembling catechu, usually of a brittle consistence and dark reddish-brown colour, consisting of the inspissated gum or juice of various trees and shrubs of tropical and sub-tropical regions." Although the definition has no molecular basis (lacking mention of phenols) and uses the term gum in a nonmolecular sense, it clearly refers to the appropriate exudates. Thus gums, resins, and phenolics (including kinos) are the three major molecular classes of exudates (gum resins being a combination), although we have found other small classes, including balsams, guaiacs, and xanthics (Lambert, Santiago-Blay, and Anderson 2008; Santiago-Blay and Lambert 2007, Lambert et al. 2013a and 2013b).

Plants that produce exudates. Exudates are produced only in vascular plants, of which the spermatophytes (seed-producing plants) provide the predominant example, although a few ferns also are producers. Modern spermatophytes comprise gymnosperms (cycads, ginkgos, conifers, and gnetophytes), and angiosperms (flowering plants). Exudates from ferns, cycads, ginkgos, and gnetophytes have yet to be examined thoroughly by spectroscopic methods. We have examined extensively the nuclear magnetic resonance (NMR) spectrum of exudates from the conifer subclass of gymnosperms and found that they are almost all resins (Lambert et al. 2007a; Lambert et al. 2007b). Angiosperms consist of a number of classes, as listed in Figure 1 (based on Angiosperm Phylogeny Group 2009). Of these, only the core eudicots have been studied extensively, including the rosids (Lambert et al. 2007c, Lambert et al. 2009, Lambert et al. 2013a) and the asterids (Lambert et al. 2013b). Both rosids and asterids exhibit a variety of molecular classes, including the three primary ones and the smaller ones, as well as some examples that fall into none of the classifications. 


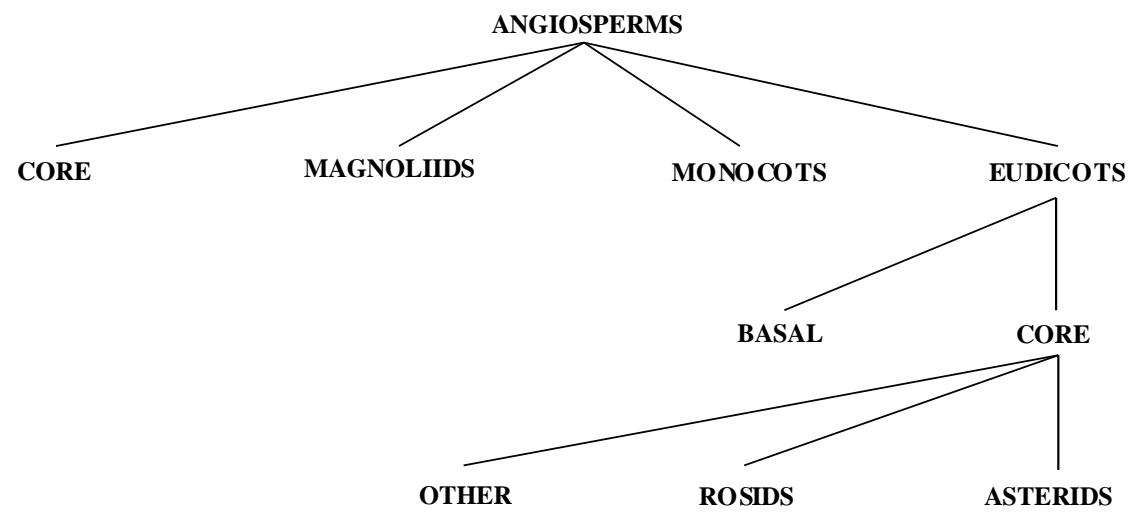

Figure 1. Simplified phylogenetic tree of the angiosperms.

In this study, we have characterized angiosperm exudates from the magnoliids, the monocots, the basal eudicots, and the core eudicots other than rosids and asterids. The magnoliids and the monocots diverged from the angiosperm lineage prior to the eudicots, most likely in the Jurassic period, some 160 Mya (Zeng et al. 2014). The basal eudicots diverged earlier than the other eudicots, as early as 125 Mya (Sun et al. 2011). Many of these groups produce abundant and important examples of exudates, although exudate production appears to be much rarer than in the rosids and the asterids. Nussinovitch (2010) mentions only 11 species from these groups in his compilation of hundreds of gums, the vast majority of which are from rosids or asterids. Langenheim (2003) provides a full overview of the plant family in her Figure 25 , but finds only three orders from these classes (Asparagales, Arecales, and Saxifragales) to be exudate producers, and of these most examples are phenolic and not true (terpenoid) resins. We have obtained and analyzed 78 exudates from 10 orders and 14 families, whose characterization by NMR spectroscopy we present herein. The angiosperms (Figure 1) comprise the magnoliids, monocots, and eudicots, in addition to four unaffiliated orders (core angiosperms), none of which have known exudate producers. Herein we describe the molecular classes of the magnoliids, the monocots, and the remaining classes of eudicots not previously investigated by NMR spectroscopy. As in our previous studies of eudicots, we use four variants of NMR spectroscopy: one-dimensional (1D) hydrogen (proton, ${ }^{1} \mathrm{H}$ ) spectra of solutions, two-dimensional (2D) hydrogen spectra of solutions of the type known as COrrelation SpectroscopY (COSY), fully decoupled carbon-13 $\left({ }^{13} \mathrm{C}\right)$ spectra of solids, and partially decoupled ${ }^{13} \mathrm{C}$ spectra of the type known as dipolar dephasing or interrupted decoupling (Lambert et al. 2011). Each method is used essentially for pattern analysis for each sample, in addition to assignment of broad classes of functionality. Description of instrumentation parameters and 
data processing may be found in our studies of eudicot exudates (e.g., Lambert et al. 2013a). All ${ }^{1} \mathrm{H}$ spectra are at $500 \mathrm{MHz}$, and all ${ }^{13} \mathrm{C}$ spectra are at 100.544 $\mathrm{MHz}$.

\section{Magnoliids}

The magnoliids are a major group of flowering plants, but much smaller than the monocots and the eudicots. In the APG III system (Angiosperm Phylogeny Group 2009), the magnoliids comprise four orders: the Canellales, the Laurales, the Magnoliales, and the Piperales. Among the better known plants in the magnoliids are avocado, cinnamon, magnolia, nutmeg, and (black) pepper. The class is characterized by pollen with a single pore, through which the pollen tube emerges, and by trimerous flowers, that is, flowers composed of assemblages of three petals or sepals. Exudates are rarely found in these orders. We have acquired and investigated six exudates from three of the four orders.

We have four samples from the order Canellales. The bark of Canella winterana is a spice similar to cinnamon, so that the tree is commonly known as wild or white cinnamon. The ${ }^{13} \mathrm{C}$ spectrum of the sample (1339, Figure 2$)$ from $C$. winterana of the Canallaceae contains extensive peaks in the unsaturated region $(\delta$ ca. $115-165)$ but also in the saturated $(\delta$ ca. 10-40) and electronwithdrawing group ( $\delta$ ca. 40-110) regions, in other words across the entire spectrum. This pattern is indicative of phenolic exudates (Lambert et al. 2007c).
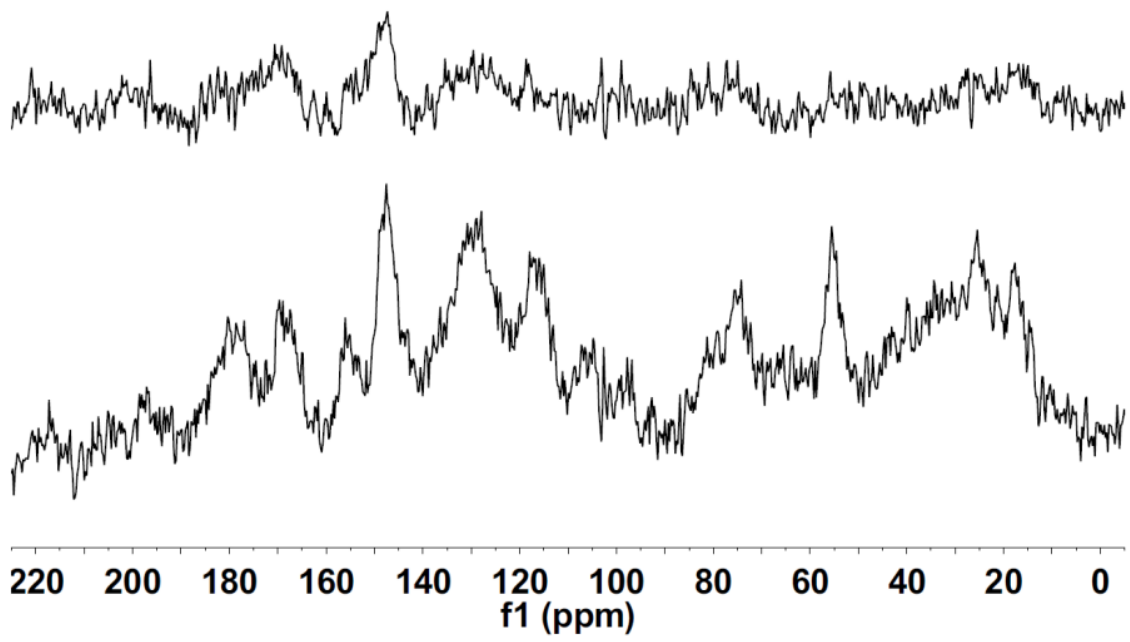

Figure 2. The ${ }^{13} \mathrm{C}$ spectrum with normal (lower) and interrupted (upper) decoupling of sample 1339 (Canella winterana). The peaks at $\delta 66,78,97,105,166,178,197$, and 205 are spinning sidebands of the peaks at $\delta 116,128,147$, and 155 . These are artifacts of the spinning process. 
Phenol itself has its resonance at $\delta 155$ and anisole (methoxybenezene) at $\delta 160$. Common kinos are characterized by two sharp resonances at 144 and 154, but Class D kinos (from the genus Corymbia rather than Eucalyptus) lack the peak at $\delta 155$. Specifically, the spectrum of $C$. winterana contains, mostly likely, aromatic peaks at $\delta 116,128,147$ (the largest peak in the spectrum), and 155, very similar to kinos but with different intensity patterns. The material was insoluble in chloroform, but a good ${ }^{1} \mathrm{H}$ spectrum (Figure 3) was obtained in the more polar solvent dimethyl sulfoxide (DMSO). There are strong aromatic and saturated resonances.

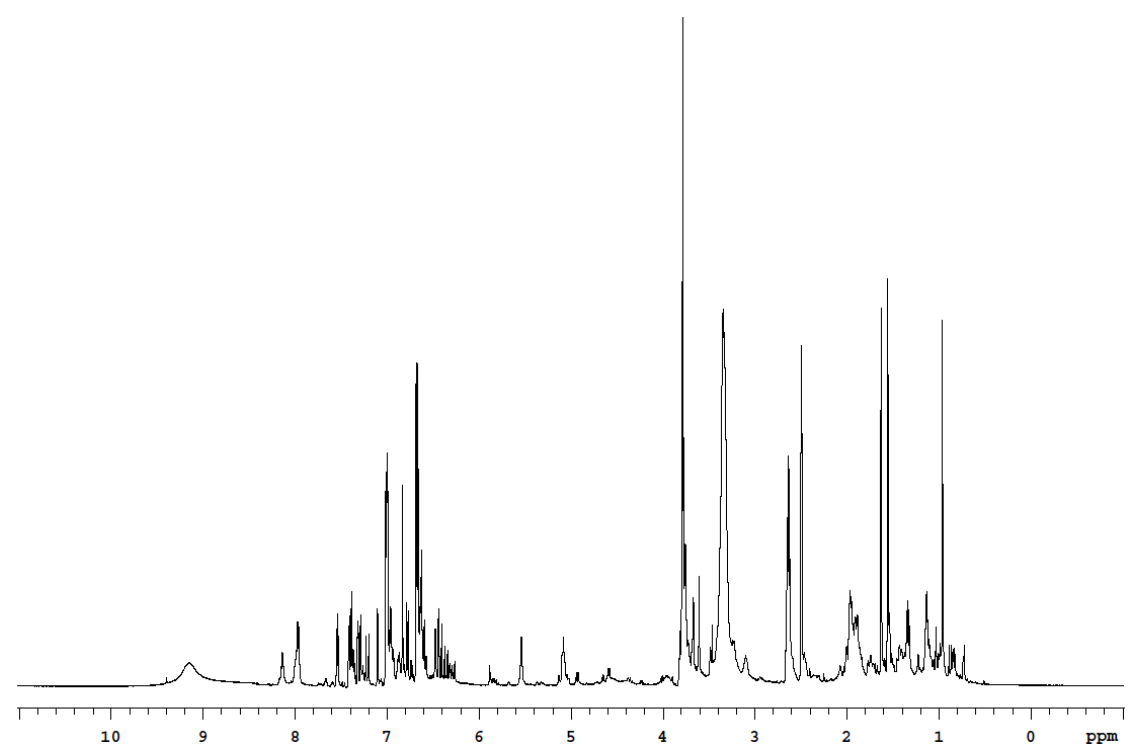

Figure 3. The $500 \mathrm{MHz}{ }^{1} \mathrm{H}$ spectrum of sample 1339 (Canella winterana) in DMSO- $d_{6}$.

The sample from Myristica globosa (556), related to nutmeg (M. fragrans), from the order Magnoliales and the family Myristicaceae, gives a typical kino spectrum (Figure 4). With interrupted decoupling the spectrum practically overlays that of other Class A and B kinos (Lambert et al. 2007c), and, most importantly, exhibits the two classic, dominant peaks at $\delta 144$ and 154 . The presence of peaks at $\delta 16-50$ (the saturated region) for $C$. winterana contrasts with most kinos, indicating more aliphatic contributions in this case. 


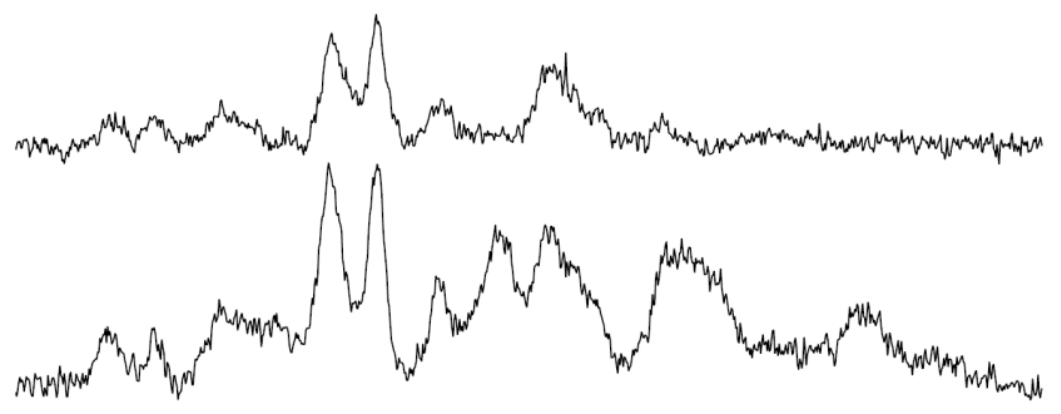

\section{$\begin{array}{lllllllllll}220 & 200 & 180 & 160 & 140 & \begin{array}{c}120 \\ \mathrm{f} 1(\mathrm{ppm})\end{array} & 80 & 60 & 40 & 20 & 0\end{array}$}

Figure 4. The ${ }^{13} \mathrm{C}$ spectrum with normal (lower) and interrupted (upper) decoupling of sample 556 (Myristica globose). The peaks at $\delta 94,104,194$, and 204 are spinning sidebands of the peaks at $\delta 144$ and 154. These are artifacts of the spinning process.

Sample 720 from Virola sp., also from the Myristicaceae, gives a ${ }^{13} \mathrm{C}$ spectrum that clearly is of a resin or wax (Figure 5). Almost all the resonances are in the saturated region, although there also is a sharp peak at $\delta 174$ in the carbonyl region. There are no resonances in the unsaturated region. Virola is well known for producing hallucinogenic alkaloids from what has been described as a dark red resin from the bark (Schultes, Hofmann, and Rätsch 2001). Our exudate is salmon colored and lacks the aromatic resonances expected of alkaloids. The ${ }^{1} \mathrm{H}$ spectrum is very simple, with several dominating singlets between $\delta 0.9$ and 2.3, and a small, so-called AX quartet at $\delta 4.1$ and 4.3 .

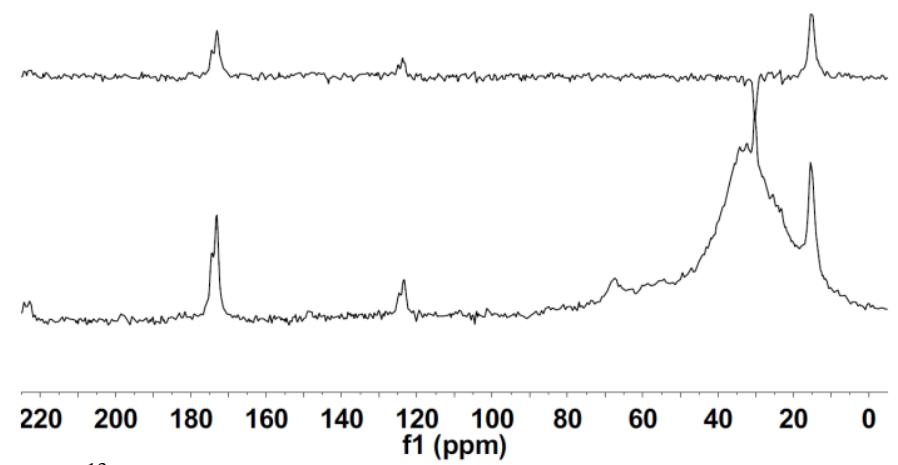

Figure 5. The ${ }^{13} \mathrm{C}$ spectrum with normal (lower) and interrupted (upper) decoupling of sample 720 (Virola sp.). The peaks at $\delta 123$ and 223 are spinning sidebands of the peak at $\delta 173$. 
The exudate from Miliusa tomentosa of the Annonaceae (1139) exhibits the classic ${ }^{13} \mathrm{C}$ pattern of a gum, but with weak saturated resonances and a strong carbonyl resonance at $\delta 174$ (Figure 6). Consequently, we classify it as a gum resin.
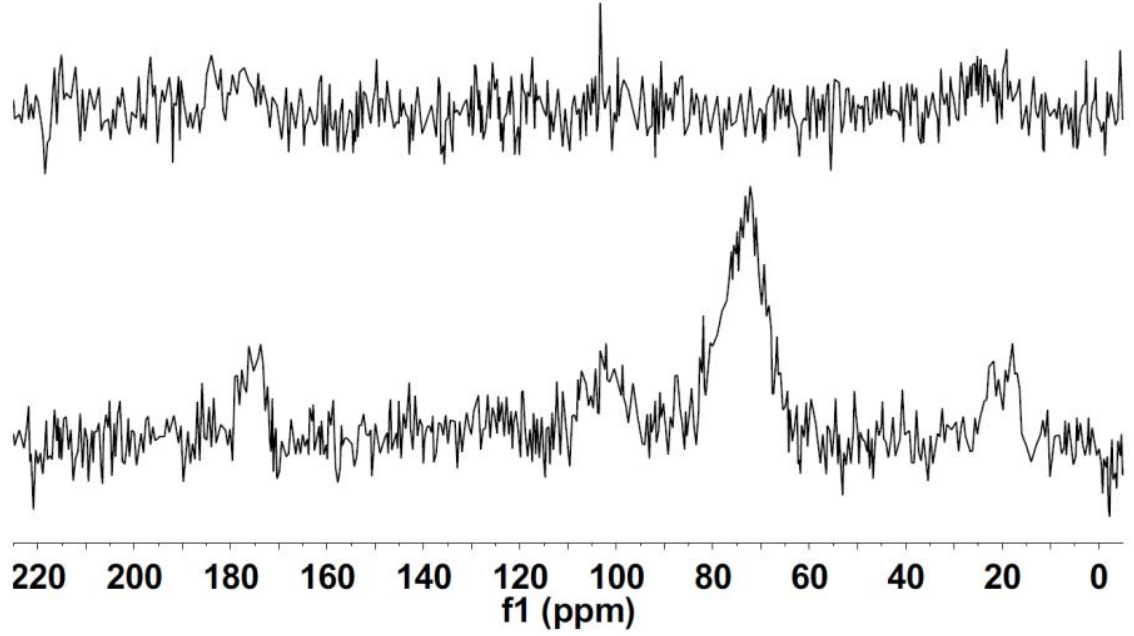

Figure 6. The ${ }^{13} \mathrm{C}$ spectrum with normal (lower) and interrupted (upper) decoupling of sample 1139 (Miliusa tomentosa).

The sample from Liriodendron tulipifera (the tulip tree, 366) exhibits a very unusual ${ }^{13} \mathrm{C}$ spectrum, containing only a series of singlets in the electronwithdrawing region between $\delta 58$ and 102, unlike the patterns of any of our known molecular classes of exudates. Finally, the ${ }^{13} \mathrm{C}$ spectrum of Piper nigrum (black pepper) of the Piperaceae (1447) also is extraordinarily unusual Figure 7).

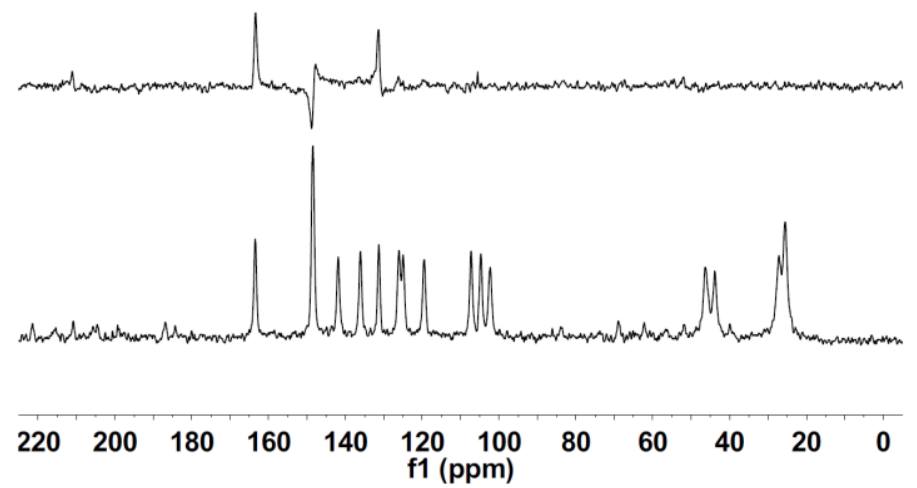

Figure 7. The ${ }^{13} \mathrm{C}$ spectrum with normal (lower) and interrupted (upper) decoupling of sample 1447 (Liriodendron tulipifera). 
There are strong peaks throughout the unsaturated region $(\delta 100-163)$ and in the saturated region $(\delta 26,44$, and 47$)$. This pattern does not fall into any known molecular class. The aromatic region in the ${ }^{1} \mathrm{H}$ spectrum has a rich collection of peaks between $\delta 6$ and 7.4, with small peaks at $\delta 1.6,1.7,3.5$ and 3.6 in chloroform (Figure 8). The pattern is very similar in DMSO but with slightly different resonance positions.

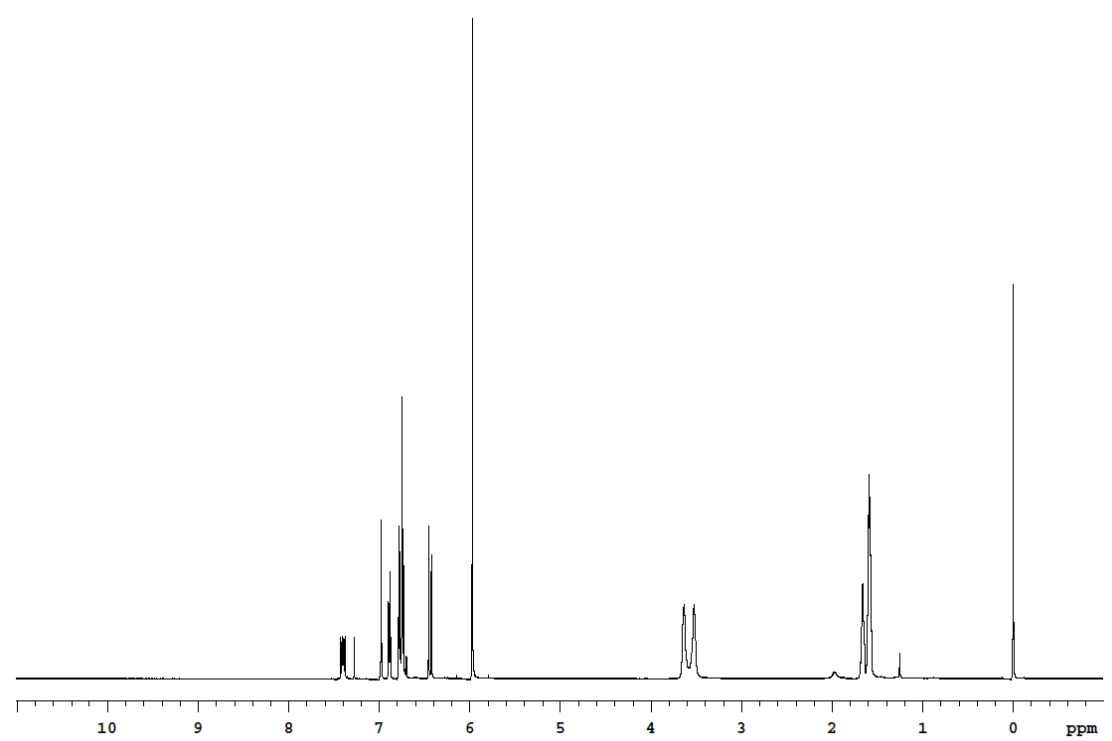

Figure 8. The $500 \mathrm{MHz}{ }^{1} \mathrm{H}$ spectrum of sample 1447 (Liriodendron tulipifera) in $\mathrm{CDCl}_{3}$.

Thus the exudates of the magnoliids are extremely diverse. The six exudates we have managed to collect belong to six different molecular classifications.

\section{Monocots}

Monocots are characterized by exhibiting a single seed leaf or cotyledon on sprouting. According to molecular phylogenetics, the monocots are monophyletic, that is, they all are descendants of a common ancestor and constitute a clade. The monocots comprise seven basal orders and the commelinid clade. The commelinids in turn comprise four orders and one unplaced family. We have acquired and analyzed exudates from only one of the basal orders, the Asparagales, and from three of the four commelinid orders.

Asparagales. This order dates only from 1977 (Huber), drawn mostly from the Liliales. Although circumscribed genetically, the order is more difficult to define morphologically. Most species are herbaceous, but some are climbers, 
succulents, or trees. The order probably diverged from the monocots early in the Cretaceous period, 120-130 Mya. It includes food plants (onion, leek, asparagus), plants that provide flavorings (vanilla), plants valued for their flowers (iris, orchid, day lilies, hosta), and desert plants (agave, Joshua tree). Because many of these plants are herbaceous, exudates tend to be rare, except in the woody genera or those with densely packed stem tissue.

We have analyzed samples from 21 species from the Asparagales, all but one of which are from the family Xanthorrhoeaceae. The single species is an agave (Agave sp.), a desert plant well known for its uses for food, drink, and clothing. Until recently, it was classified into its own family, the Agavaceae, but, in the APG III system (2009), it falls within the subfamily Agavoideae of the Asparagaceae. Our single sample (961) proved to be a gum according to its ${ }^{13} \mathrm{C}$ spectra (Figure 9). There are small resonances in the saturated region, insufficient to classify the material as a gum resin. In Figure 6 the resin resonances are as strong as the carbohydrate (anomeric) peak at ca. $\delta 104$, whereas in Figure 9 the resin resonance is much less intense.
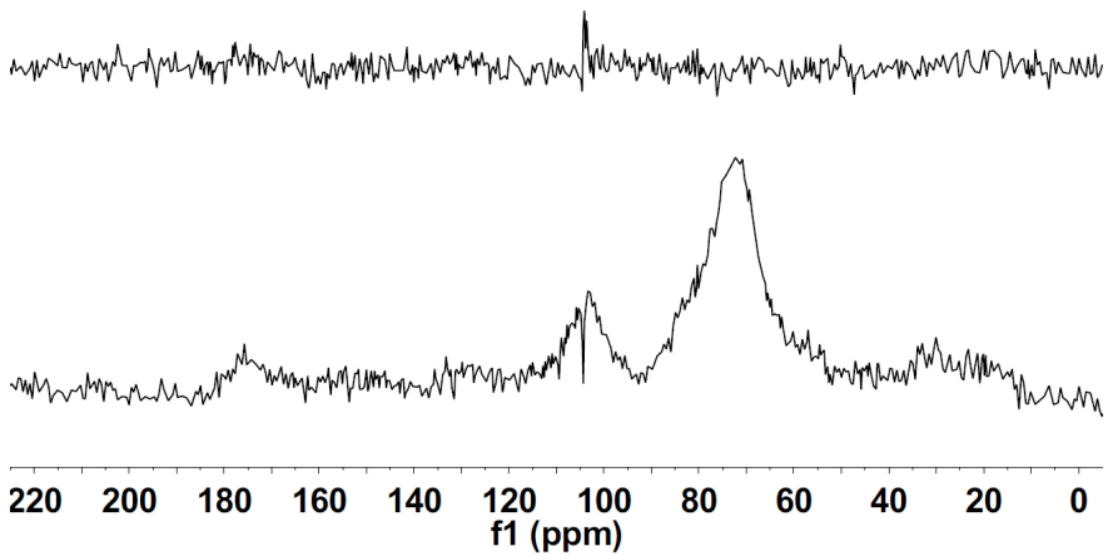

Figure 9. The ${ }^{13} \mathrm{C}$ spectrum with normal (lower) and interrupted (upper) decoupling of sample 961 (Agave sp.).

The Xanthorrhoeaceae comprise three subfamilies (Asphodeloideae, Hemerocallidoideae, and Xanthorrhoeoideae), which formerly were classified as families (Asphodelaceae, Hemerocallidaceae and Xanthorrhoeaceae). We have found and analyzed exudates from all three subfamilies: ten from the Asphodeloideae, one from the Hemerocallidoideae, and nine from the Xanthorrhoeoideae.

All of our samples from the subfamily Asphodeloideae are members of the genus Aloe, which constitutes the monophyletic tribe Aloeae. The remaining genera within this family are nonmonophyletic, for which we have no exudates. Our ten samples include two of $A$. ferox, four of $A$. succotrina, and four of $A$. 
vera. All but one have basically the same, unique ${ }^{13} \mathrm{C}$ spectrum, as illustrated in Figure 10 for sample 1115 (A. vera). These spectra constitute a new molecular class of exudates, whose NMR spectra provide a unique diagnostic. The general Aloe spectra contain weak peaks in the saturated region at $\delta 20-50$, strong peaks in the electron-withdrawing region at $\delta 55-90$, strong peaks in the unsaturated region at $\delta 110-160$, and weak peaks in the carbonyl region at $\delta 165-200$. The peak at $\delta 160$ likely is phenolic (the resonance of the 1 carbon of anisole falls at this same position). Although there have been many studies of the molecular constituents of aloes (Gjerstad 1971, Hamman 2008, Saccù, Bogoni, and Procida 2001, Zhong et al. 2013), it is difficult to determine whether any of the studies were focusing on the same plant part as we do, the solidified exudate. Investigators have variously referred to the leaf, the leaf pulp, the gel extract, or the exudate. They have found carbohydrates (glucose, mannose), anthraquinones and anthrones, enzymes, amino acids, lipids (steroids, triglycerides, uric acid), vitamins, and carboxylic acids (salicylic acid). Carbohydrate resonances are minimal in Figure 10. Our key observation is that exudates from nine different plants from three different species all give substantially the same ${ }^{13} \mathrm{C}$ NMR spectrum. The exudates generally are insoluble in common organic solvents such as chloroform, but they give good spectra in highly polar solvents such as DMSO.
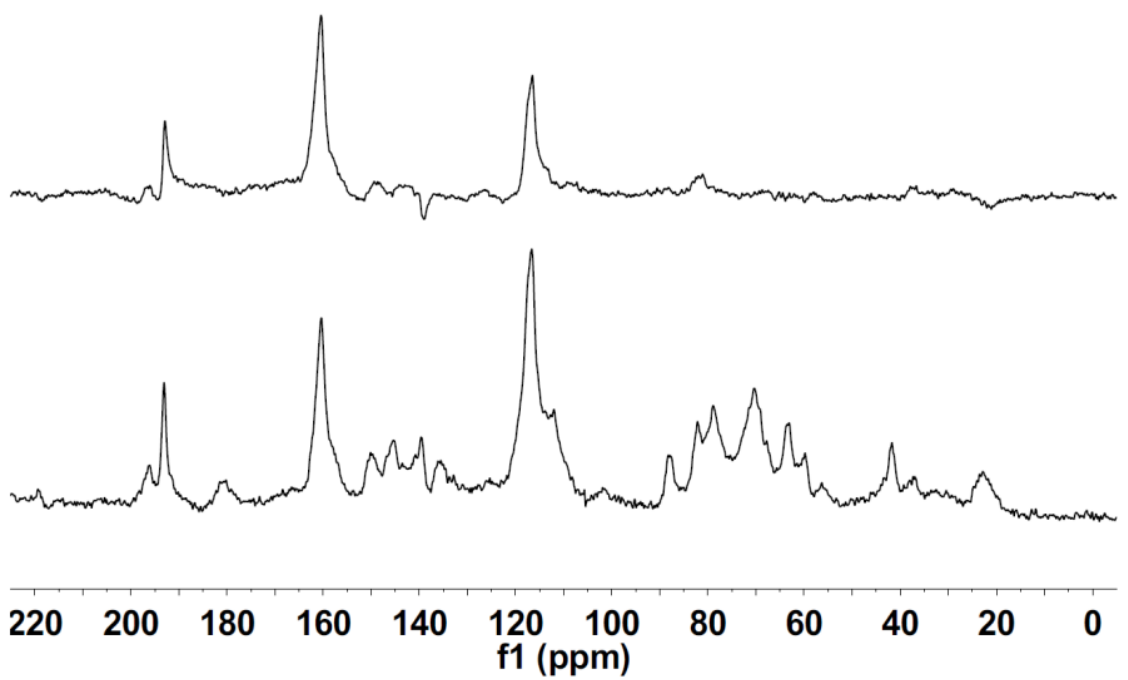

Figure 10. The ${ }^{13} \mathrm{C}$ spectrum with normal (lower) and interrupted (upper) decoupling of sample 1115 (Aloe vera). These spectra were taken with a faster spinning rate of 8000 $\mathrm{Hz}$ in order to eliminate spinning sidebands. Other spectra were taken at $5000 \mathrm{~Hz}$ unless otherwise noted. 
Figure 11 gives an example, from sample 1398. As in the ${ }^{13} \mathrm{C}$ spectra, the ${ }^{1} \mathrm{H}$ spectra show resonances in all regions. Unlike ${ }^{13} \mathrm{C}$, the ${ }^{1} \mathrm{H}$ spectra can distinguish alkenic and aromatic resonances. Figure 11 shows strong alkenic and aromatic resonances in the region $\delta$ 5.5-7.2. The peaks around $\delta 11.4$ suggest carboxylic acids. It should be noted that the ${ }^{13} \mathrm{C}$ spectra of one sample (1109) of $A$. vera gave a distinct spectrum, classically indicative of a gum resin.

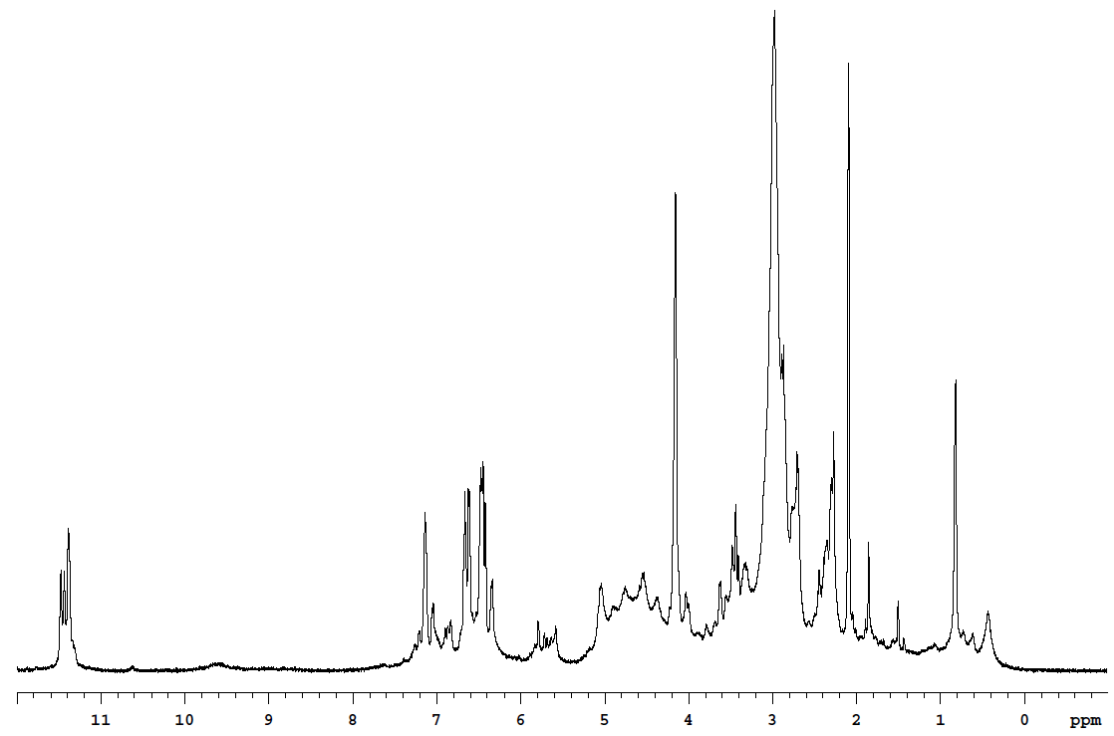

Figure 11. The $500 \mathrm{MHz}{ }^{1} \mathrm{H}$ spectrum of sample 1398 (Aloe succotrina) in deuterated dimethyl sulfoxide $\left[\mathrm{CD}_{3}(\mathrm{SO}) \mathrm{CD}_{3}\right]$.

The single sample from the subfamily Hemerocallidoideae is from the species Phormium tenax. Known as New Zealand flax, this plant produces a fiber that was important to the traditional Māori culture and today is popular ornamentally. The ${ }^{13} \mathrm{C}$ spectrum indicates that the exudate is a standard gum.

All nine samples from the subfamily Xanthorrhoeoideae are from the genus Xanthorrhoea, with four species represented and one sample without species identification. The name is derived from the Greek (xanthos) for yellow, but the materials vary from cinnamon to yellowish red to dark brown. This common Australian plant previously was called blackboy but now is widely known as the grass tree or grass gum-tree (for its production of exudate). Australian aborigines used the exudate as an adhesive in the production of spears, vessels, and even didgeridoos (the indigenous wind instrument). Without exception, the ${ }^{13} \mathrm{C}$ spectra indicate a phenolic nature of the exudates, with a pattern distinct from kinos. The spectra of sample 841 is given in Figure 12 for X. australis. 


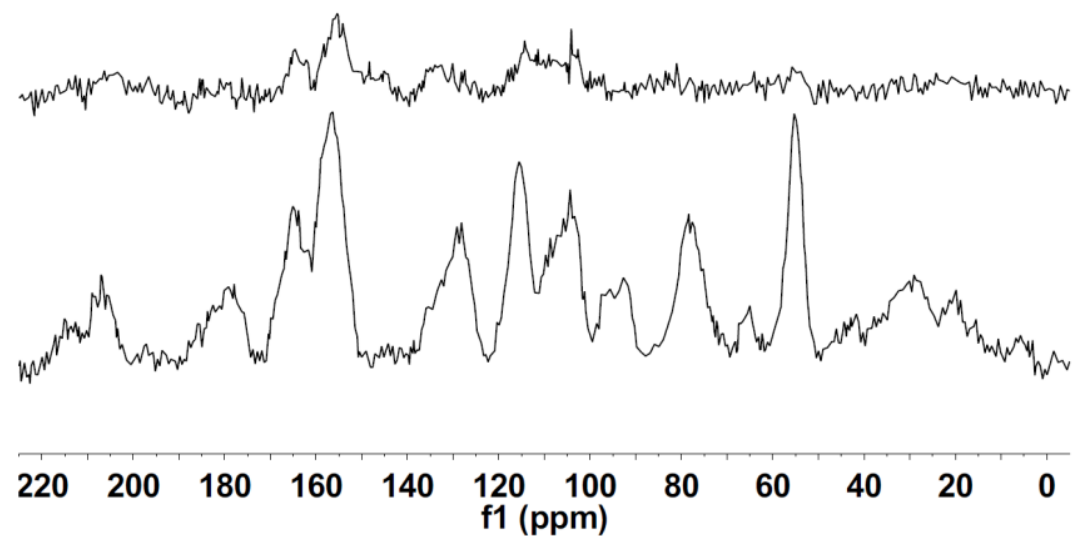

Figure 12. The ${ }^{13} \mathrm{C}$ spectrum with normal (lower) and interrupted (upper) decoupling of sample 841 (Xanthorrhoea australis). The peaks at $\delta 178,205$, and 214 are spinning sidebands of the peaks at $\delta 128,155$, and 164, as are peaks in the region 78, 105, and 114, which are obscured by other peaks. These are artifacts of the spinning process.

Many of the spectra of these nine samples have a peak-for-peak similarity. The phenolic peak at $\delta 156$ is dominant. The ${ }^{1} \mathrm{H}$ spectra in chloroform similarly have peaks in all regions, as in Figure 13, also for sample 841. Peaks in the alkenic and aromatic regions $\delta 6-7.5$ and in the electron-withdrawing $\delta 2-4$ are strong, and there is an aldehydic peak at $\delta 9.9$. Off scale, there also is a small carboxylic acid peak at $\delta 12$.

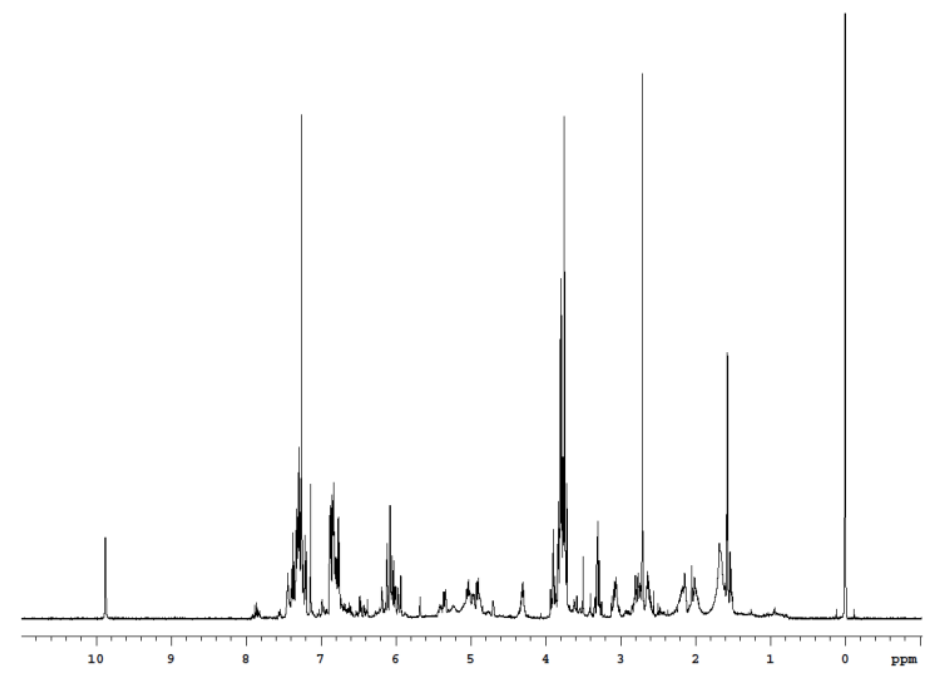

Figure 13. The $500 \mathrm{MHz}{ }^{1} \mathrm{H}$ spectrum of sample 841 (Xanthorrhoea australis) in $\mathrm{CHCl}_{3}$. 
Arecales. This monophyletic family is part of the clade commelinids. It contains only one family, the Arecaceae, which comprise the palm trees and have been known previously as the Palmae or the Palmaceae. We have acquired and analyzed 22 samples from 4 subfamilies, 14 genera, and 16 species (Table 1). Six of the seven samples from the subfamily Arecoideae are simple gums, including two samples from the genus Syagrus such as the queen palm $(S$. romanzoffiana), three from the genus Roystonea (the royal palm), and one from the genus Prestoea (the mountain cabbage palm). The single exception within the Arecoideae is sample 1007, attributed to the species Cocos syagrus at the time it was collected by the Field Museum from Brazil. We cannot say for certain what this species is, but the syagrus palm comprises its own genus, many species of which originally belonged to the genus Cocos, such as Syagrus romanzoffiana (synonym C. romanzoffiana). The ${ }^{13} \mathrm{C}$ spectrum (Figure 14) of this sample contains only a single, sharp peak at $\delta 32$, indicating that the molecular structure contains many, similar saturated carbon atoms, as in the long chains of waxes. There is a similarity with the spectra of resins, which, however, usually cover a much larger range within the saturated region and have multiple peaks. This pattern is seen in a few other samples in this study, including in Figure 5 and other examples to be discussed in due course.

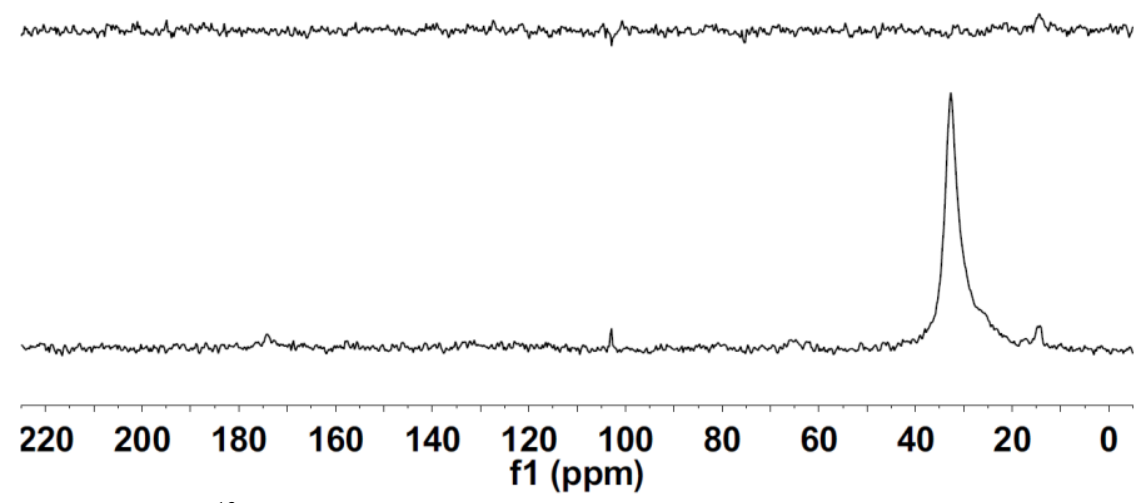

Figure 14. The ${ }^{13} \mathrm{C}$ spectrum with normal (lower) and interrupted (upper) decoupling of sample 1007 (Cocos syagrus).

The subfamily Calamoideae of the Arecaceae contains one genus of rattan palms, Daemonorops draco, which has been famous since antiquity for its bright red exudate called dragon's blood. This term also has been applied to exudates from other genera, including Croton, Dracaena, Pterocarpus, and Calamus. It has been used as a pigment, a medicine, and a varnish (Langenheim 2003). Four of our five exudates from this subfamily are from $D$. draco, and three of these have characteristic phenolic patterns (Figure 15 for sample 1146) in the ${ }^{13} \mathrm{C}$ spectrum, including a strong peak at $\delta 155$. This material is not a phenolic resin 
in the polymer sense, so it is incorrect to refer to the exudate as a resin. Arnone et al. (1997) have identified many of the molecular components. Sample 609 of this same species, however, yielded an exudate that proved to be a simple resin, lacking almost all resonances in the unsaturated region. This species offers another example of plants that exude different molecular materials. Indeed, Piozzi, Passannanti, and Paternostro (1974) reported diterpenes from D. draco. The fifth sample (1498) from this subfamily is from the sago palm (Metroxylon sagu), and the exudate is a simple gum.
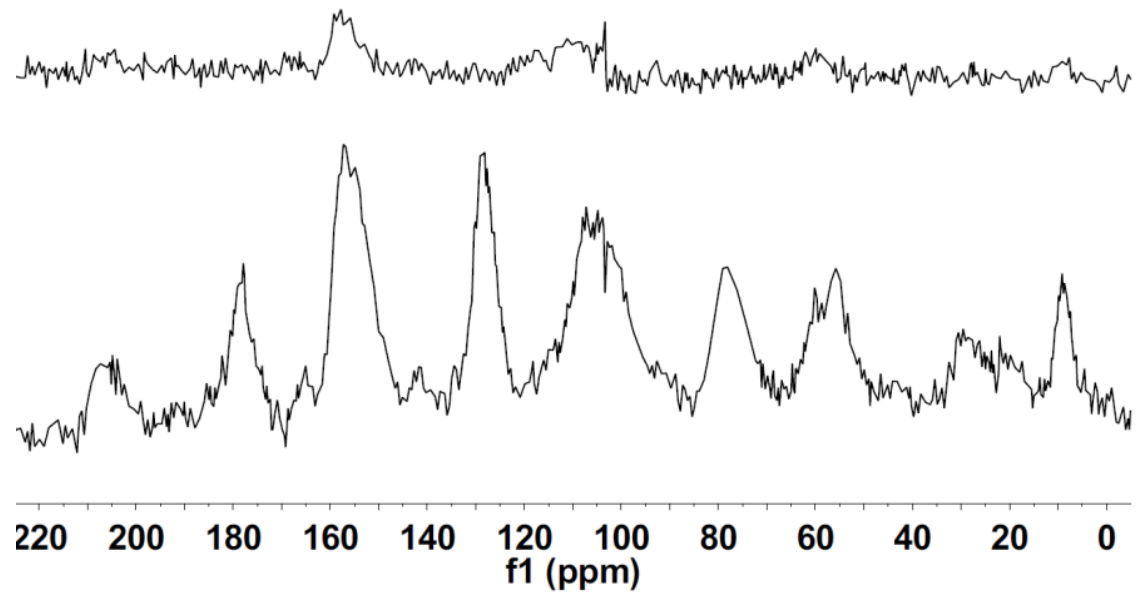

Figure 15. The ${ }^{13} \mathrm{C}$ spectrum with normal (lower) and interrupted (upper) decoupling of sample 1146 (Daemonorops draco). The peaks at $\delta 177$ and 205 and portions of those at $\delta 77$ and 105 are spinning sidebands of the peaks at $\delta 127$ and 155 . These are artifacts of the spinning process.

We have analyzed a single sample (1004) from the subfamily Ceroxyloideae, from the Ceroxylon sp., the Andean wax palm. Its ${ }^{13} \mathrm{C}$ spectra indicate that the exudate is a resin. Interestingly, the ${ }^{13} \mathrm{C}$ spectrum is very similar to the spectrum of 609 from $D$. draco, although the similarity is less apparent in the ${ }^{1} \mathrm{H}$ spectra.

We have nine samples from the subfamily Coryphoideae from seven different genera and species. The molecular types are quite varied. Six samples produce exudates that are gums: Caryota urens, Corypha utan (the cabbage palm), Livistona chinensis (the Chinese fan palm), Pritchardia sp. (fan palms), and Sabal palmetto (sabal or cabbage palm). The exudate from Phoenix rupicola, a type of date palm, is a gum resin, whose ${ }^{13} \mathrm{C}$ spectrum also contains a strong carbonyl resonance. The ${ }^{13} \mathrm{C}$ spectra of the two samples (1009 and 1135) of Copernicia prunifera contain just a single peak at $\delta 32$, very likely indicative of a wax. Whereas the ${ }^{13} \mathrm{C}$ spectra of sample 1009 are very similar to those of 
sample 1007 (Cocos syagrus) with a single sharp peak, those of sample 1135 (Figure 16) are broad like the spectra of sample 720 (Virola sp., Figure 5). Thus this subfamily provides gum, gum resin, and wax exudates.

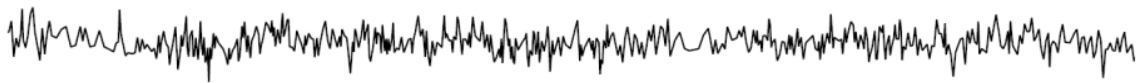

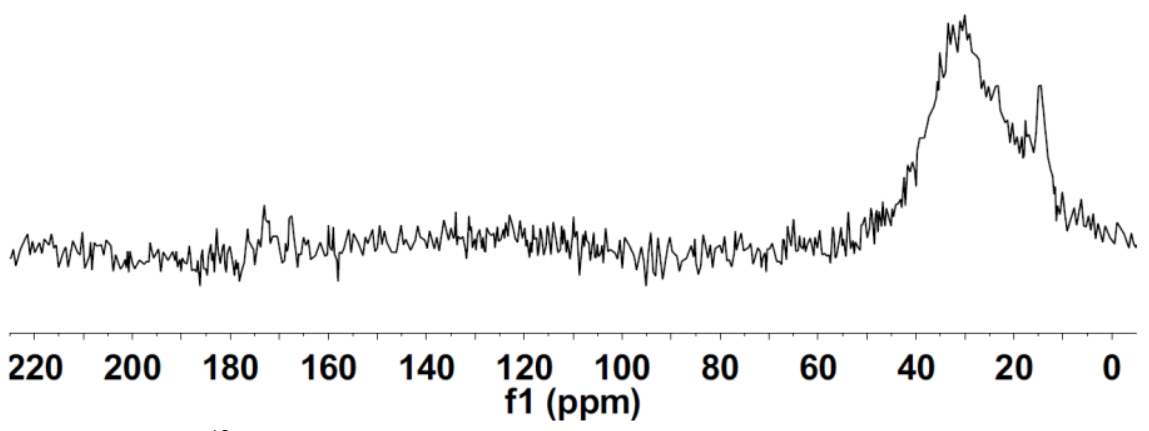

Figure 16. The ${ }^{13} \mathrm{C}$ spectrum with normal (lower) and interrupted (upper) decoupling of sample 1135 Virola sp.).

Poales. This order is economically important on a global basis and includes bromeliads, sedges, and grasses (wheat, rice, maize, barley, and sugarcane), most of which are not exudate producers. We have obtained six samples from two families, four genera, and four species. Like the Coryphoideae, these exudates are quite varied. Two are gums (Tillandsia utriculata of the Bromeliaceae, a bromeliad called spreading airplant, and Zea mays, the common grain called maize or corn). Stipa tenacissama (esparto grass) of the family Poaceae and the subfamily Pooideae gives a single peak in the ${ }^{13} \mathrm{C}$ spectrum, suggesting a wax. Sample 948 of Saccharum officinarum (sugarcane) from the family Poaceae and the subfamily Panicoideae has a somewhat broader version of the same spectrum, but identical with dipolar dephasing, so this material likely is a wax also. The material is insoluble in chloroform, despite its hydrocarbon nature, suggesting a high, waxy polymer. Samples 1462 and 1463, also of Saccharum officinarum, give ${ }^{13} \mathrm{C}$ spectra that are very similar to the spectrum of sucrose. For example, the peaks at $\delta 92$ and 102 correspond to the anomeric carbons, respectively, of the glucose and fructose rings, and the peak at $\delta 82$ corresponds to $\mathrm{C} 5$ of fructose. The remaining peaks fall into the region $\delta$ $60-75$, in agreement with the positions for the other carbons of both rings.

Zingiberales. This small order contains a variety of mostly tropical plants, including banana, canna lily, heliconia, ginger, and cardamom. We have analyzed the exudates from two samples, both from the banana genus (Musa). Whereas sample 379 is a gum, sample 1192 (Figure 17) has the single peak at $\delta$ 32 in common with several other samples we have characterized as waxes. The 
peak is not so sharp as those of samples 1004 and 1007, they are sharper than those of 720 and 1135 .
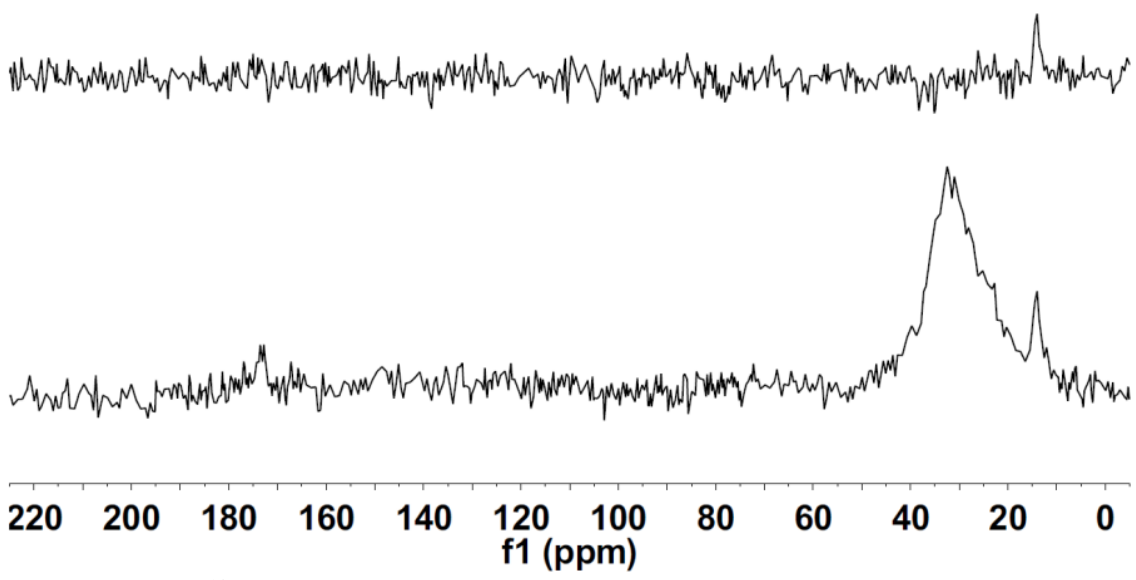

Figure 17. The ${ }^{13} \mathrm{C}$ spectrum with normal (lower) and interrupted (upper) decoupling of sample 1192 (Musa acuminata).

\section{Basal Eudicots}

As already noted and illustrated in Figure 1, in the APG III system (2009) the eudicots comprise core plants plus some five orders of basal plants. Of the basal eudicots, we have examined a single sample (1144) from the family Ranunculaceae (order Ranuncales), Xanthorhiza simplicissima (yellowroot). The ${ }^{13} \mathrm{C}$ spectrum (Figure 18) is typical of phenolic materials, with the characteristic peak at $\delta 150-155$. Xanthorhiza simplicissima is known to contain the alkaloid berberine, which contains several phenolic-like carbons. The peaks from the known ${ }^{13} \mathrm{C}$ and ${ }^{1} \mathrm{H}$ spectra of berberine, however, form a very minor component in the corresponding spectra of this exudate, which is composed of a more complex mixture of aromatic and other compounds. The ${ }^{1} \mathrm{H}$ spectrum in chloroform (Figure 19) lacks resonances in the saturated region, but contains numerous resonances in the electron-withdrawing, alkenic ( $\delta$ ca. 5-6.5), and aromatic regions ( $\delta$ ca. $6.5-8)$, and has sharp peaks in the aldehydic $(\delta 9.5)$ and carboxylic regions $(\delta 12)$. 


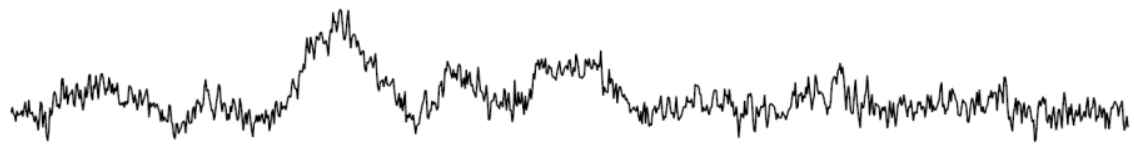

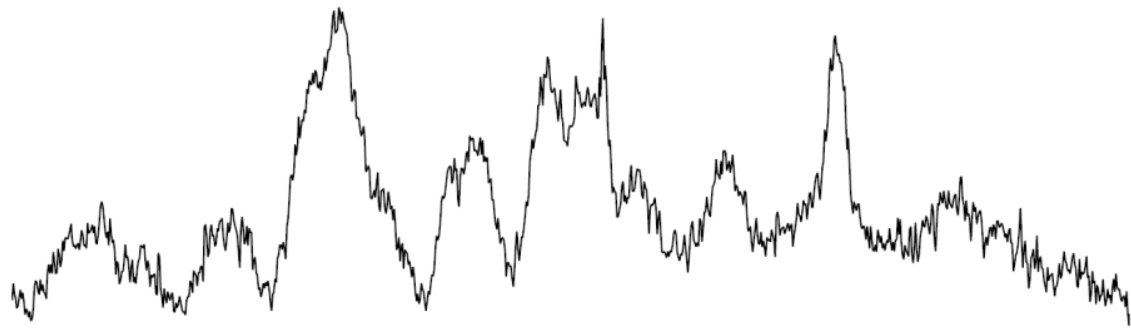

\section{$\begin{array}{llllllllllll}220 & 200 & 180 & 160 & 140 & 120 & 100 & 80 & 60 & 40 & 20 & 0\end{array}$ f1 (ppm)}

Figure 18. The ${ }^{13} \mathrm{C}$ spectrum with normal (lower) and interrupted (upper) decoupling of sample 1144 (Xanthorhiza simplicissima). The peaks at $\delta 180$ and 208 and portions of those at $\delta 80$ and 108 are spinning sidebands of the peaks at $\delta 130$ and 158 . These are artifacts of the spinning process.

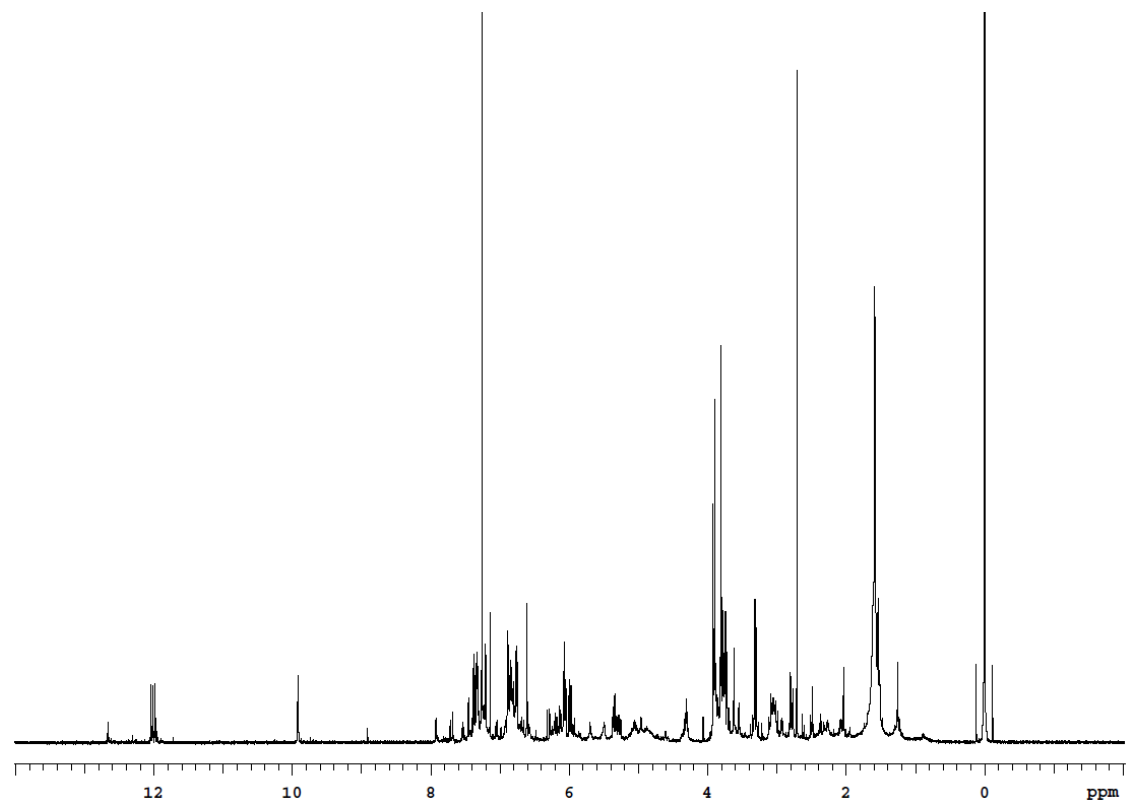

Figure 19. The $500 \mathrm{MHz}{ }^{1} \mathrm{H}$ spectrum of sample 1144 (Xanthorhiza simplicissima) in $\mathrm{CDCl}_{3}$. 


\section{Core Eudicots Other Than Rosids and Asterids}

Saxifragales. We have obtained four exudates from the single family, the Altingaceae, in this order. This family contains only three genera, of which Semiliquidambar may be a hybrid of the other two, Altingia and Liquidambar (Ickert-Bond and Wen 2006). Our three exudates from the species Liquidambar styraciflua (sweet gum) and the single sample from the closely related Altingia excelsa give similar solid state ${ }^{13} \mathrm{C}$ and solution ${ }^{1} \mathrm{H}$ spectra, with important variations.

The name storax has been given to the exudates of the Altingaceae (Langenheim 2003). Langenheim reports that exudate from the trunk of Liquidambar is primarily phenolic in nature, whereas leaf exudates are primarily terpenoid (resins). She also reports that these exudates closely resemble those of the genus Styrax of the Styracaceae in the clade asterids. None of the four samples we analyzed was phenolic or aromatic, in contrast to balsam exudates from the asterids (Lambert et al. 2013b). All four were characteristically resins according to the ${ }^{13} \mathrm{C}$ spectra (Figure 20). The pattern in the saturated region is the same in all four samples, indicating a very similar molecular composition, primarily presumably of terpenes, for all the samples. All samples have strong unsaturated resonances in the region $\delta 110-140$ with large spinning sidebands.

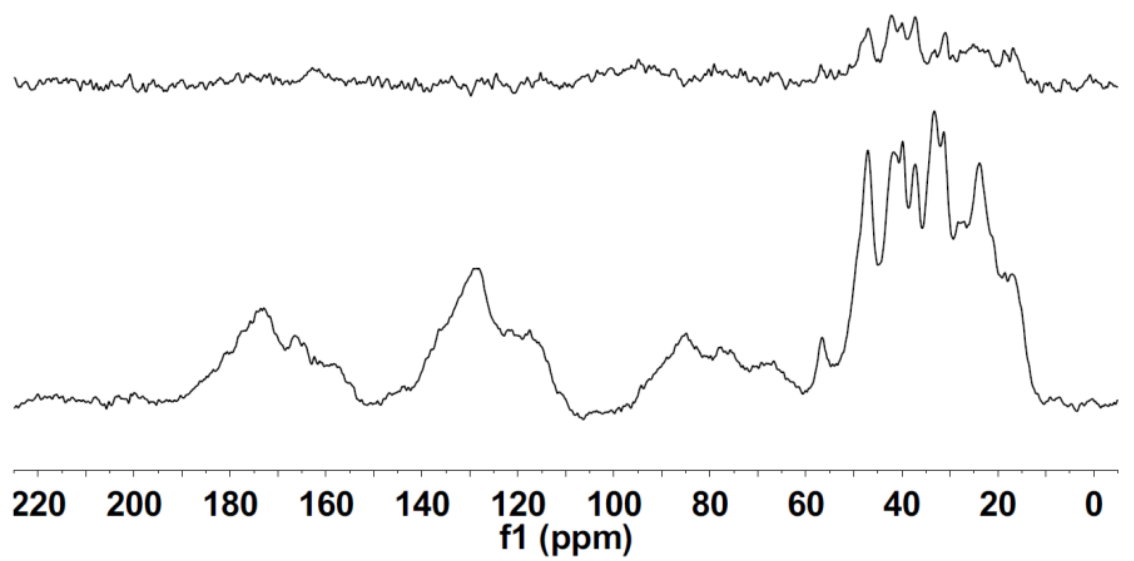

Figure 20. The ${ }^{13} \mathrm{C}$ spectrum with normal (lower) and interrupted (upper) decoupling of sample 327 (Liquidambar styraciflua). The peaks at $\delta$ 65-115 and 155-185 are spinning sidebands of the peaks at $\delta 110-140$. These are artifacts of the spinning process.

In the spectrum of sample 1607 (Figure 21) the same patterns are present, but the unsaturated resonances are decidedly sharper. The peaks at $\delta 117$ and 130 do not correspond to the peaks of styrene, polystyrene, or cinnamyl alcohol, but hey do resemble the alkenic resonances of cinnamic acid. 


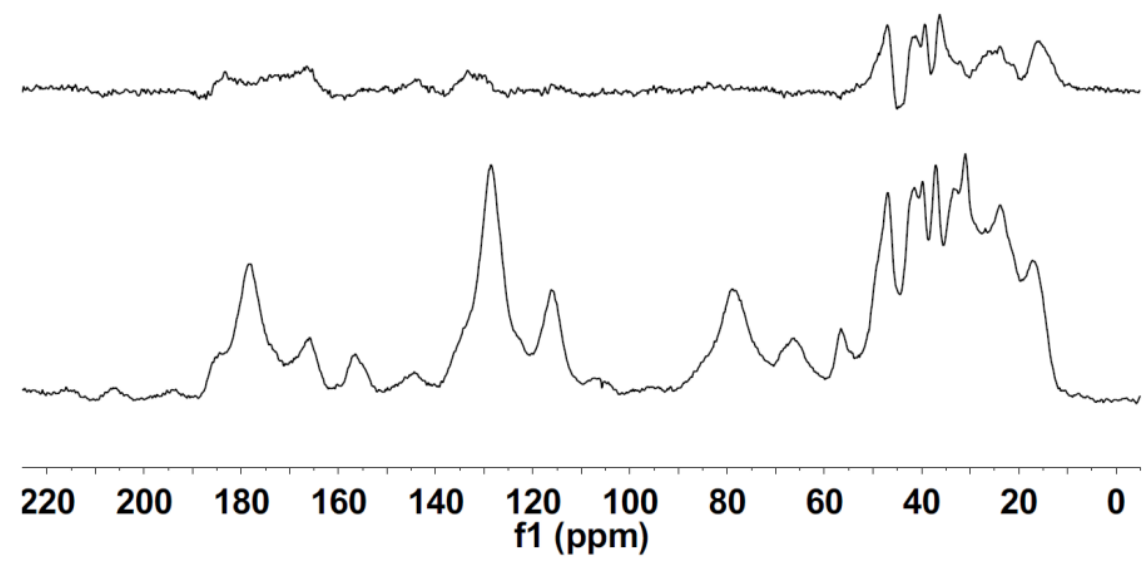

Figure 21. The ${ }^{13} \mathrm{C}$ spectrum with normal (lower) and interrupted (upper) decoupling of sample 1607 (Liquidambar styraciflua). The peaks at $\delta$ 65-115 and 155-185 are spinning sidebands of the peaks at $\delta 110-140$. These are artifacts of the spinning process.

The ${ }^{1} \mathrm{H}$ spectra of the exudates from samples 327 and 968 are almost identical (Figure 22), although they came from different sources. There are strong aromatic resonances, strong saturated resonances, and weak electronwithdrawing resonances, which do not correspond to resonances from styrene or cinnamyl alcohol, but there are peaks at $\delta 6.4,7.4$, and 7.8 that could come from cinnamic acid. None of the samples has strong carbon peaks at $\delta 150-160$ indicative of phenolic functionalities. The exudate is best termed a resin possibly admixed with cinnamic acid. As these materials are primarily resinous in nature, they do not confirm the previous characterization of storax exudates as phenolic (Langenheim 2003). There is no evidence for phenols in the spectra. There are at least two explanations for these observations. (1) Langenheim characterized leaf exudates as resinous. Our sources did not provide information about the tree part from which the material was harvested. Possibly our resinous exudates were from the leaves and her phenolic exudates from another plant part. (2) Our observations are based on ${ }^{13} \mathrm{C}$ spectra of the bulk exudate, whereas previous conclusions were drawn from experiments carried out on extracts that do not represent the bulk. The previous observations may have been unrepresentative of the bulk. 


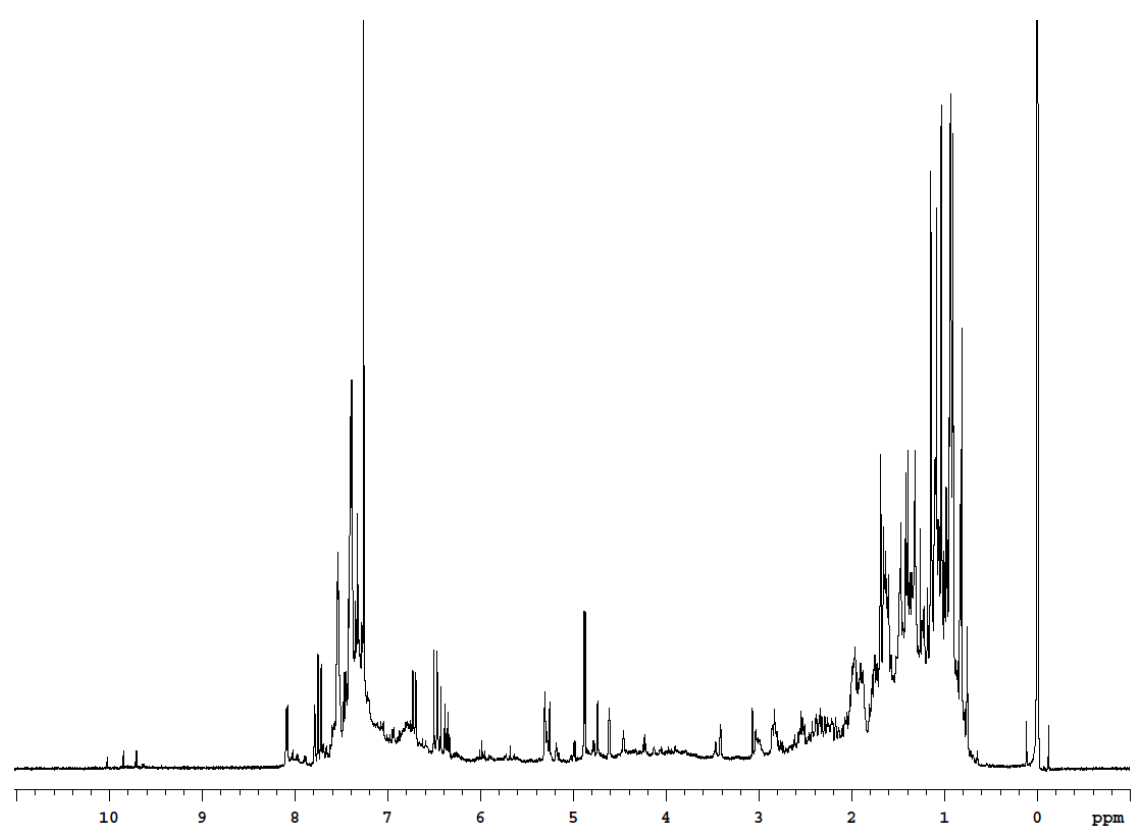

Figure 22. The $500 \mathrm{MHz}{ }^{1} \mathrm{H}$ spectrum of sample 327 (Liquidambar styraciflua) in $\mathrm{CHCl}_{3}$.

Caryophyllales. The Cactaceae of this order are strong exudate producers. Although there are 33 families in this order, we have found exudates only from the Cactaceae, representing three different subfamilies. Gums by far are the representative molecular type in this family. Our two samples from the Pereskioideae are gums. The genus Pereskia, an unusual genus of cacti with leaves, may be basal within the Cactaceae rather than a subfamily (Edwards, Nyffeler, and Donoghue 2005). For the Cactoideae, the single sample (842) from Carnegiea gigantea is a gum, but the two samples from the genus Mammillaria are gum resins. The two samples are from different species, but both give nearly the same spectra, with strong resinous peaks and much weaker gum peaks. Of the 12 samples from the subfamily Opuntioideae, 11 give typical gum spectra. Figure 23 provides an example (sample 617, Opuntia sp.), in which there is more fine structure than normal within the resonance for the $\mathrm{C}$ $\mathrm{O}$ carbons of gums. Most of these are from the genus Opuntia (the prickly pear), but two are from Cylindropuntia (the cholla cactus). The single exceptional sample (1204) may not be a true exudate. It was the color of sandstone and extremely hard. The ${ }^{13} \mathrm{C}$ spectrum had only a single peak at $\delta$ 168 , in the carbonyl region. The material does not appear to be organic. 

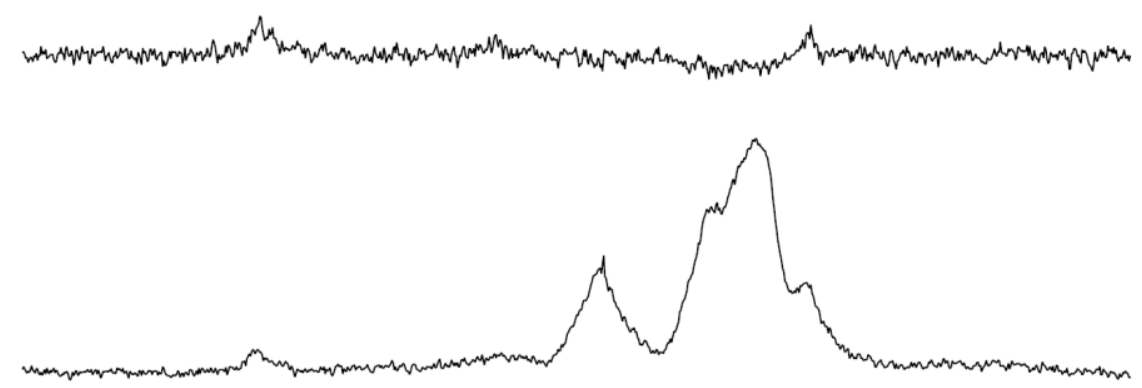

\section{$\begin{array}{lllllllllll}220 & 200 & 180 & 160 & 140 & \begin{array}{c}120 \\ \mathrm{f} 1(\mathrm{ppm})\end{array} & 80 & 60 & 40 & 20 & 0\end{array}$}

Figure 23. The ${ }^{13} \mathrm{C}$ spectrum with normal (lower) and interrupted (upper) decoupling of sample 617 (Opuntia sp.).

\section{Summary and Conclusions}

Plants bearing seeds appeared during the Late Devonian Period, some 370 Mya (Labandeira 2007). Gymnosperms appeared during the Carboniferous Period (ca. 300-360 Mya) and flourished during the Jurassic Period (ca. 145-200 Mya) (Reece et al. 2013), when flowering plants (angiosperms) first appeared (Zeng et al. 2014). In this investigation, we have classified exudates of the earliest of the flowering plants according to their molecular constituents as determined by NMR spectroscopy, a primary method for the elucidation of molecular structure (Lambert et al. 2011). According to Zeng et al. (2014), the monocots and the magnoliids appeared during the Jurassic Period. The eudicots followed in the Cretaceous Period (66-145 Mya). This monophyletic clade is divided into the basal and the core eudicots (Worberg et al. 2007). The basal eudicots may have appeared as early as 125 Mya (Sun et al. 2013). The core eudicots comprise the rosids and the asterids, as well as other important genera. The current investigation focused on the exudates from these early flowering plants, including the monocots, the magnoliids, the basal eudicots, and the core eudicots other than the already studied rosids and asterids.

The six magnoliid exudates proved to represent six distinct molecular classes. In addition to a resin, a gum resin, a kino, and a non-kino phenolic, the exudates of two species (Piper nigrum and Liriodendron tulipifera) exhibited spectra not seen before, indicating new molecular types.

Our monocot samples numbered 51. Of these, 21 came from the Asparagales, all from the Xanthorrhoeaceae. Ten of these were from the genus Aloe, of which nine gave a unique spectral type, characteristic for this genus (Figures 7 and 8). The ${ }^{13} \mathrm{C}$ and ${ }^{1} \mathrm{H}$ spectra were dominated by peaks in the electron-withdrawing region. There were few peaks in the saturated region, but there were significant aromatic and carboxylic resonances. In addition, nine 
Asparagales samples were from the genus Xanthorrhoea, all of which gave a unique and diagnostic ${ }^{13} \mathrm{C}$ spectral type (Figure 12) indicating a phenolic material distinct from kinos, confirmed by the ${ }^{1} \mathrm{H}$ spectra (Figure 13). From the commelinids, we analyzed 22 members of the Arecales, all from the Arecaceae (palm trees). Over half of these produced gums, but there also were three waxes and one gum resin. Also, the genus Daemonorops draco (dragon's blood palm) produced a characteristic phenolic pattern (Figure 15) in three of our four samples (the fourth was a resin). The remaining commelinids, including the Poales and the Zingiberales, produced gums, waxes, and (in the case of Saccharum officinarum) probably sucrose.

Our single example of an exudate from the basal eudicot order Ranuncales was a phenolic.

There are two important groups of exudates from the core eudicots other than rosids and asterids. Cacti from the Cactaceae (order Caryophyllales) are strong exudate producers. Of our 18 samples, 14 were gums, three were gum resins, and one was unclassified. The second important group, called storax, came from the order Saxifragales, family Altingaceae, and genera Altingia and Liquidambar. Although Langenheim (2003) described these materials as phenolics, we find that they are terpenoid resins, possibly with cinnamic acid, but without phenols. The name storax thus poses a problem. It derives from the genus Styrax of the Styracaceae, order Ericales, and clade asterales. The plants thus are not closely related, nor are their respective exudates molecularly similar. We have called the exudates from Styrax balsams (Lambert et al. 2013b), but their common (and molecularly inappropriate) names include benzoin resin, gum benjamin, and styrax balsam. It is clear that exudates from the Altingaceae ("storax") and from genus Styrax of the Styracaceae (balsam) are not structurally analogous (Figures 20 and 21), although both probably contain cinnamic acid. Storax is a resin, whereas balsam contains largely nonphenolic aromatic constituents. The materials are quite distinct and should not be conflated. We retain the term balsam for the exudates of Styrax. In Table 1 we have called the exudates of the Altingaceae "resin (other)" because of the strong aromatic component seen in the ${ }^{13} \mathrm{C}$ spectra and confirmed by the ${ }^{1} \mathrm{H}$ spectra, which is not present in most spectra of resins. Possibly "aromatic resin" would be an appropriate class name, as distinguished from terpenoid resins, which primarily are "aliphatic resins."

Of the 78 exudates in this study, 32 proved to be gums, which therefore is the dominant exudate type in these clades. There also are five gum resins. In second place are phenolics (14), not counting one kino. We have nine materials classified as aloes, whose spectra contain strong resonances in the electronwithdrawing region, plus unsaturated resonances that may include phenols. As phenolic resonances are minor, the aloe exudates should not be classified as phenolics. They appear to be sui generis, justifying the new class simply called 
aloes. There are 6 waxes and only 3 resins, plus the four aromatic resins of the Altingaceae. Four materials had unique, unclassified spectra.

\section{Acknowledgments}

The authors are grateful to the Welch Foundation (Departmental Grant No. W-0031), the Camille and Henry Dreyfus Senior Scientist Mentor Program, and The Pennsylvania State University, York Campus, for financial support of this research.

\section{Literature Cited}

Angiosperm Phylogeny Group. 2009. An update of the Angiosperm Phylogeny Group classification for the Orders and Families of flowering plants: APG III. Botanical Journal of the Linnean Society. 161(2):105-121. http://dx.doi.org/10.1111/j.1095-8339.2009.00996.x

Arnone, A., G. Nasini, O. V. de Pava, and L. Merlini. 1997. Constituents of Dragon's Blood. 5. Dracoflavans $\mathrm{B}_{1}, \mathrm{~B}_{2}, \mathrm{C}_{1}, \mathrm{C}_{2}, \mathrm{D}_{1}$, and $\mathrm{D}_{2}$, New A-Type Deoxyproanthocyanidins. Journal of Natural Products. 60:971-975. http://dx.doi.org/10.1021/np9702188

Edwards, E. J., R. Nyffeler, and M. J. Donoghue. 2005. Basal cactus phylogeny: Implications of Pereskia (Cactaceae) paraphyly for the transition to the cactus life form. American Journal of Botany. 92:1177-1188. http://dx.doi.org/10.3732/ajb.92.7.1177

Gjerstad, G. 1971. Chemical studies of Aloe vera juice I: Amino acid analysis. Advancing Frontiers of Plant Sciences 28:311-315.

Hamman, J. H. 2008. Composition and applications of Aloe vera leaf gel. Molecules. 13:15991616. http://dx.doi.org/10.3390/molecules 13081599

Huber, H. 1977. The Treatment of Monocotyledons in an Evolutionary System of Classification. Plant Systematics and Evolution. Supplement 1: 285-298. doi: 10.1007/978-3-7091-70762_18.

Ickert-Bond, S. M., and J. Wen. 2006. Phylogeny and Biogeography of Altingiaceae: Evidence from Combined Analysis of Five Non-coding Chloroplast Regions. Molecular Phylogenetics and Evolution 39(2):512-528. http://dx.doi.org/10.1016/j.ympev.2005.12.003

Labandeira, C. 2007. The Origin of Herbivory on Land: Initial Patterns of Plant Tissue Consumption by Arthropods. Insect Science 14:259-275. doi:10.1111/j.17447917.2007.00152.x.

Lambert, J. B., E. W. Donnelly, E. A. Heckenbach, C. L. Johnson, M. A. Kozminski, Y. Wu, and J. A. Santiago-Blay. 2013a. Molecular Classification of the Natural Exudates of the Rosids. Phytochemistry 94:171-183. http://dx.doi.org/10.1016/j.phytochem.2013.06.013

Lambert, J. B., S. Cronert, H. F. Shurvell, and D. A. Lightner. 2011. Organic Structural Spectroscopy. Second Edition. Prentice Hall. Boston, Massachusetts. 533 pp.

Lambert, J. B., E. A. Heckenbach, A. E. Hurtley, Y. Wu, and J. A. Santiago-Blay. 2009. Nuclear magnetic resonance spectroscopic characteristics of legume exudates. Journal of Natural Products 72:1028-1035. http://dx.doi.org/10.1021/np900188j

Lambert, J. B., M. A. Kozminski, C. A. Fahlstrom, and J. A. Santiago-Blay. 2007a. Proton Nuclear Magnetic Resonance Characterization of Resins from the Family Pinaceae. Journal of Natural Products 70:188-195. http://dx.doi.org/10.1021/np060486i

Lambert, J. B., M. A. Kozminski, and J. A. Santiago-Blay. 2007b. Distinctions among conifer exudates by proton magnetic resonance spectroscopy. Journal of Natural Products 70:1283-1294. http://dx.doi.org/10.1021/np0701982

Lambert, J. B., C. L. Johnson, E. W. Donnelly, E. A. Heckenbach, Y. Wu, and J. A. Santiago-Blay. 2013b. Exudates from the Asterids: Characterization by Nuclear Magnetic Resonance Spectroscopy, Life: The Excitement of Biology 1:17-52. http://dx.doi.org/10.9784/LEB1(1)Lambert.03

Lambert, J. B., J. A. Santiago-Blay, and K. B. Anderson. 2008. Chemical signatures of fossilized resins and recent plant exudates. Angewandte Chemie, International Edition in English 47:9608-9616. Angewandte Chemie 120:9750-9760. http://dx.doi.org/10.1002/anie.200705973 
Lambert, J. B., Y. Wu, M. A. Kozminski, and J. A. Santiago-Blay. 2007c. Characterization of eucalyptus and chemically related exudates by nuclear magnetic resonance spectroscopy. Australian Journal of Chemistry 60:862-870. http://dx.doi.org/10.1071/CH07163

Langenheim, J. H. 2003. Plant Resins: Chemistry, Evolution, Ecology, and Ethnobotany. Timber Press. Portland, Oregon, USA. 586 pp.

Merriam-Webster. 2003. Merriam-Webster's Collegiate Dictionary, 11th edition, MerriamWebster, Inc. Springfield, Massachusetts, USA. 1623 pp.

Nussinovitch, A. 2010. Plant Gum Exudates of the World: Sources, Distribution, Properties, and Applications. CRC Press. Boca Raton, Florida, USA. $401 \mathrm{pp}$.

Oxford English Dictionary. 2009. 2nd edition on CD-ROM (v. 4.0.0.3). Oxford University Press. Oxford, UK.

Piozzi, F., S. Passannanti, and M. P. Paternostro. 1974. Diterpenoid Resin Acids of Daemonorops draco. Phytochemistry 13:2231-2233. http://dx.doi.org/10.1016/0031-9422(74)85033-8

Reece, J. B., L. A. Urry, M. L. Cain, S. A. Wasserman, P. V. Minorsky, and R. B. Jackson. 2013. Campbell Biology. 10th Edition. Benjamin Cummings. San Francisco, California, USA. $1488 \mathrm{pp}$.

Rodríguez Ramos, R., J. Pagán Jiménez, J. A. Santiago-Blay, J. B. Lambert, and P. R. Craig. 2013. Some indigenous uses of plants in pre-Columbian Puerto Rico. Life: The Excitement of Biology 1:83-90. http://dx.doi.org/10.9784/LEB1(1)Rodriguez.09

Saccù, D., P. Bogoni, and G. Procida. 2001. Aloe Exudate: Characterization by Reversed Phase HPLC and Headspace GC-MS. Journal of Agricultural and Food Chemistry 49(10):45264530. http://dx.doi.org/10.1021/jf010179c

Santiago-Blay, J. A. and J. B. Lambert. 2007. Amber's Botanical Origins Uncovered. American Scientist 95:150-157. http://dx.doi.org/10.1511/2007.64.1020

Schultes, R. E., A. Hofmann, and C. Rätsch. 2001. Plants of the Gods: Their Sacred, Healing, and Hallucinogenic Powers, 2nd edition. Healing Arts Press. Rochester, Vermont, USA. 208 pp.

Sun G., D. L. Dilcher, H. Wang and Z. Chen. 2011. A Eudicot from the Early Cretaceous of China. Nature. 471:625-628. http://dx.doi.org/10.1038/nature09811

Worberg, A., D. Quandt, A-M Barniske, C. Löhne, K. W. Hilu, and T. Borsch. 2007. Phylogeny of Basal Eudicots: Insights from Non-coding and Rapidly Evolving DNA. Organisms, Diversity and Evolution 7:55-77. http://dx.doi.org/10.1016/j.ode.2006.08.001

Zhong, J., Y. Huang, W. Ding, X. Wu, J. Wan, and H. Luo. 2013. Chemical Constituents of Aloe barbadensis Miller and their Inhibitory Effects on Phosphodiesterase-4D. Fitoterapia 91:159165. http://dx.doi.org/10.1016/j.fitote.2013.08.027

Zeng, L., Q. Zhang, R. Sun, H. Kong, N. Zhang, and H. Ma. 2014. Resolution of deep angiosperm phylogeny using conserved nuclear genes and estimates of early divergence times. Nature Communications 5:4956. http://dx.doi.org/10.1038/ncomms5956 


\begin{tabular}{|c|c|c|c|c|c|c|c|c|c|}
\hline & 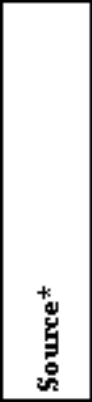 & 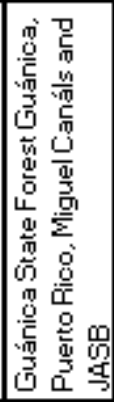 & 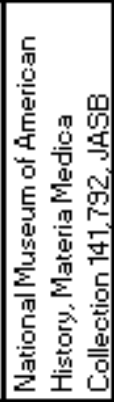 & 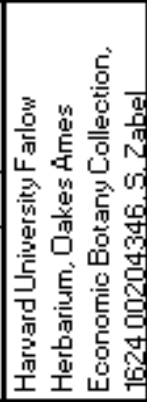 & 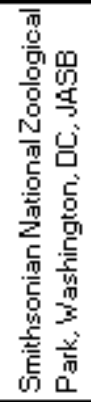 & 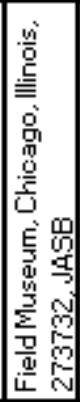 & 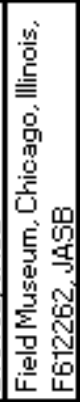 & 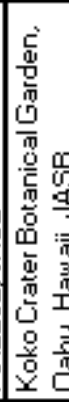 & 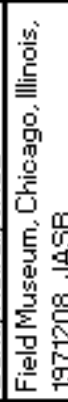 \\
\hline & 尊 & $\begin{array}{l}\frac{9}{0} \\
\frac{9}{9} \\
\frac{5}{a}\end{array}$ & $\frac{\mathrm{g}}{\mathrm{g}}$ & 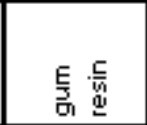 & $\frac{\overline{\mathrm{g}}}{\mathrm{s}}$ & 趇 & 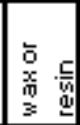 & $\begin{array}{l}\mathrm{E} \\
\text { 品 }\end{array}$ & $\frac{\mathrm{D}}{\frac{0}{10}}$ \\
\hline & 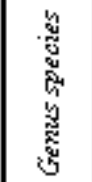 & 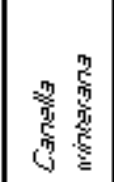 & $\begin{array}{l}\mathrm{E} \\
\text { 变 } \\
\text { 变 }\end{array}$ & 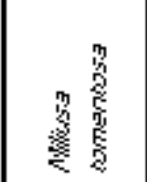 & 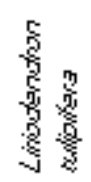 & 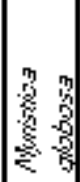 & 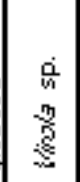 & 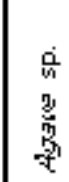 & 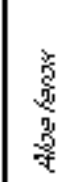 \\
\hline 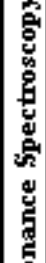 & 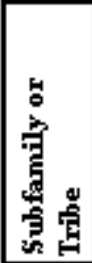 & & & & & & & 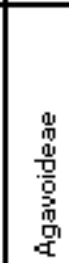 & 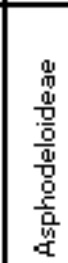 \\
\hline 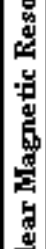 & 实 & 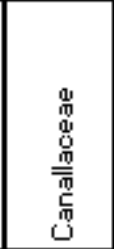 & 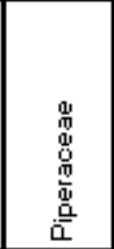 & 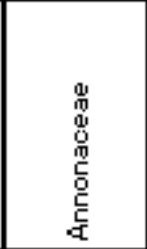 & 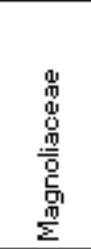 & 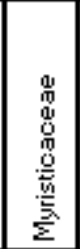 & 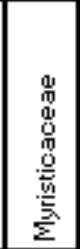 & 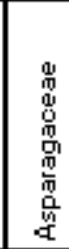 & 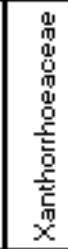 \\
\hline 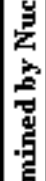 & 韋 & 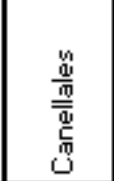 & 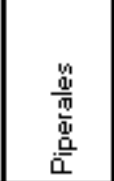 & 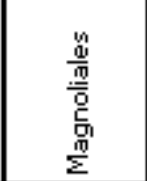 & 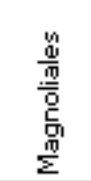 & 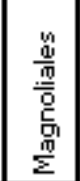 & 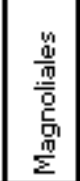 & 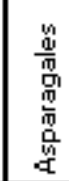 & 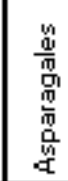 \\
\hline 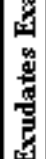 & 气ूّ & 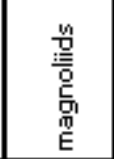 & 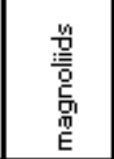 & 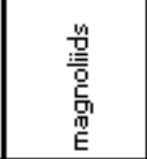 & 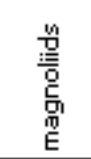 & 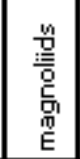 & 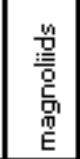 & $\begin{array}{l}\text { y } \\
8 \\
g \\
\frac{0}{0} \\
\text { E }\end{array}$ & $\begin{array}{l}\text { y. } \\
\stackrel{g}{g} \\
\frac{g}{0} \\
\mathrm{E}\end{array}$ \\
\hline ت & 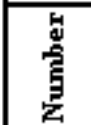 & $\stackrel{\frac{p}{\rho}}{\frac{1}{2}}$ & 等 & 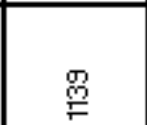 & $\bar{m}$ & 嗯 & $\mathbb{N}$ & $\dot{\Phi}$ & 5 \\
\hline
\end{tabular}




\begin{tabular}{|c|c|c|c|c|c|c|c|}
\hline 萬 & 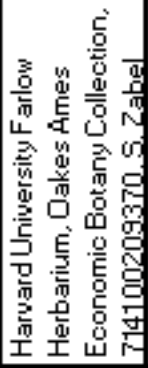 & 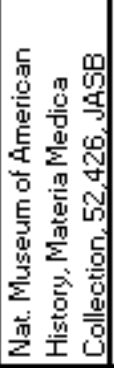 & 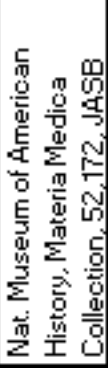 & 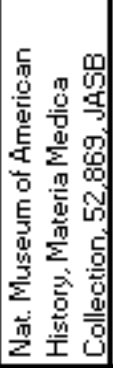 & 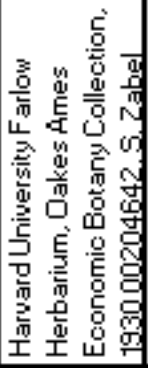 & 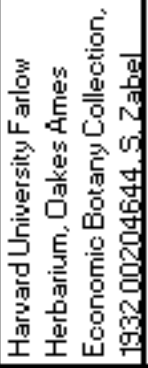 & 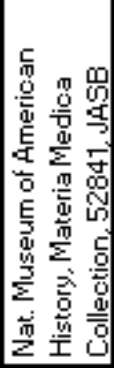 \\
\hline 密 & $\frac{9}{\frac{0}{\pi}}$ & $\frac{\mathrm{g}}{\mathrm{g}}$ & $\frac{9}{\frac{0}{\pi}}$ & $\frac{\Delta}{\frac{0}{\pi}}$ & 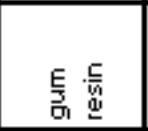 & $\frac{0}{0}$ & $\frac{9}{0}$ \\
\hline 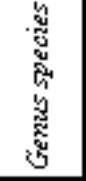 & 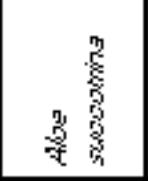 & 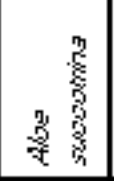 & 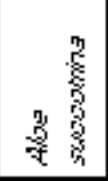 & 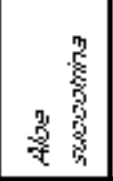 & 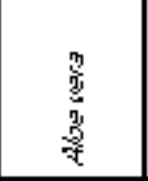 & 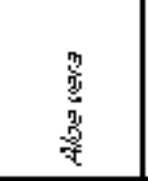 & 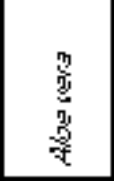 \\
\hline 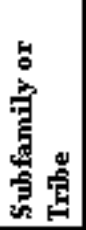 & 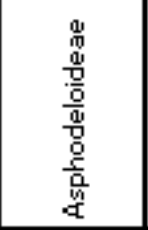 & 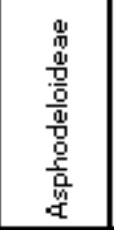 & 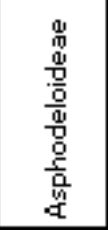 & 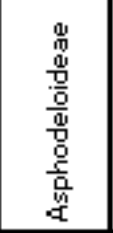 & 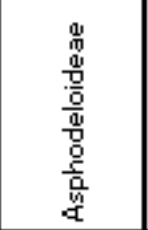 & 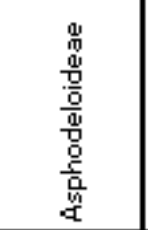 & 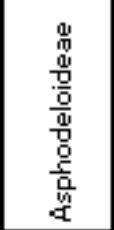 \\
\hline 常 & 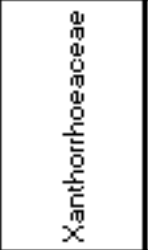 & 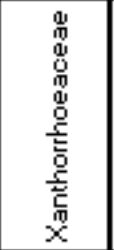 & 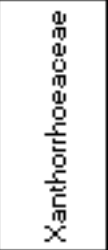 & 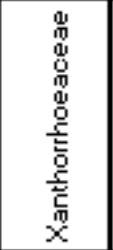 & 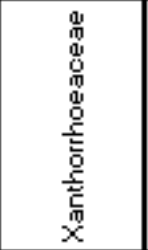 & 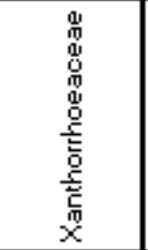 & 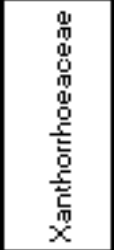 \\
\hline 売 & 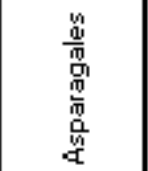 & 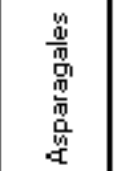 & 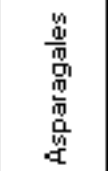 & 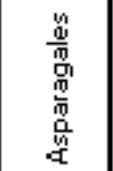 & 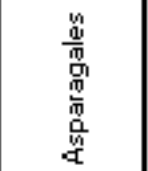 & 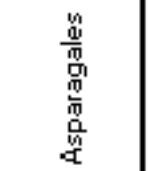 & 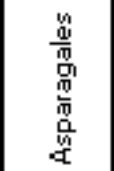 \\
\hline ఫ్ & $\begin{array}{l}y \\
\frac{9}{0} \\
\frac{0}{0} \\
\text { E }\end{array}$ & $\begin{array}{l}\text { n } \\
\stackrel{0}{0} \\
\stackrel{9}{0} \\
\text { E }\end{array}$ & $\begin{array}{l}\stackrel{y}{0} \\
\stackrel{g}{g} \\
\stackrel{5}{0} \\
\text { E }\end{array}$ & $\begin{array}{l}\stackrel{y}{0} \\
\stackrel{0}{0} \\
\stackrel{0}{0} \\
\text { E }\end{array}$ & $\begin{array}{l}\stackrel{y}{0} \\
\stackrel{9}{g} \\
\stackrel{0}{0} \\
\text { E }\end{array}$ & $\begin{array}{l}\text { y } \\
\stackrel{5}{0} \\
\frac{0}{\mathrm{C}} \\
\mathrm{o} \\
\mathrm{E}\end{array}$ & $\begin{array}{l}\text { y } \\
\stackrel{g}{0} \\
\stackrel{0}{0} \\
\text { E }\end{array}$ \\
\hline 岂 & $F$ & 璦 & 藋 & 产 & 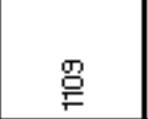 & $\stackrel{\frac{\omega 0}{\Gamma}}{\risingdotseq}$ & 品 \\
\hline
\end{tabular}




\begin{tabular}{|c|c|c|c|c|c|c|}
\hline 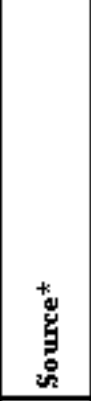 & 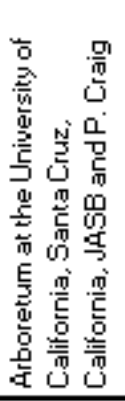 & 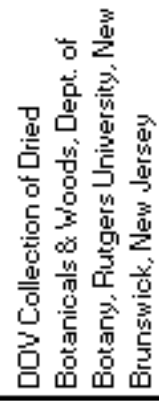 & 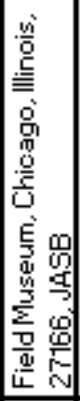 & 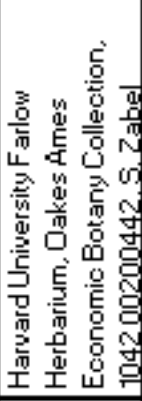 & 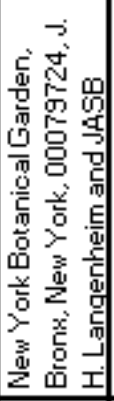 & 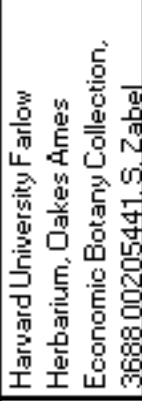 \\
\hline 㞭 & $\begin{array}{l}\text { E } \\
\text { ठे }\end{array}$ & $\begin{array}{l}\frac{9}{\bar{g}} \\
\frac{9}{9} \\
\frac{9}{2} \\
\end{array}$ & \begin{tabular}{l|}
$\frac{9}{0}$ \\
$\frac{0}{9}$ \\
$\frac{9}{a}$ \\
\end{tabular} & $\begin{array}{l}\frac{\underline{o}}{\mathrm{~g}} \\
\mathrm{c} \\
\frac{\mathrm{y}}{\mathrm{z}} \\
\end{array}$ & $\begin{array}{l}\frac{.0}{0} \\
\frac{9}{c} \\
\frac{9}{5} \\
\end{array}$ & $\begin{array}{l}\frac{.0}{0} \\
\frac{9}{\mathrm{c}} \\
\frac{\mathrm{g}}{\mathrm{a}} \\
\end{array}$ \\
\hline 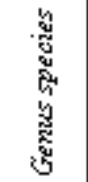 & 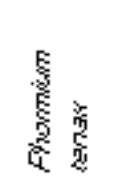 & 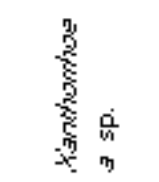 & 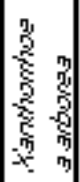 & 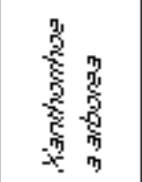 & 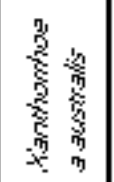 & 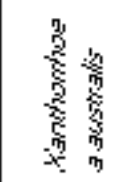 \\
\hline 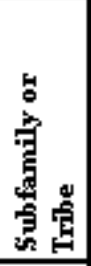 & 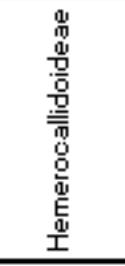 & 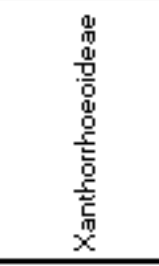 & 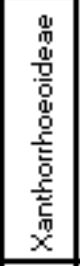 & 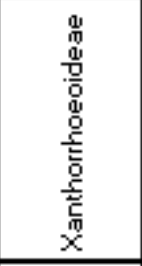 & 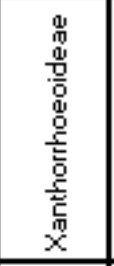 & 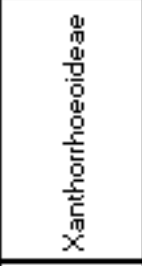 \\
\hline 光 & 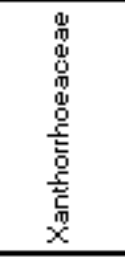 & 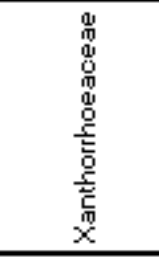 & 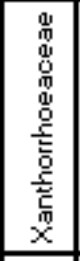 & 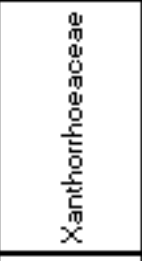 & 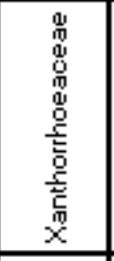 & 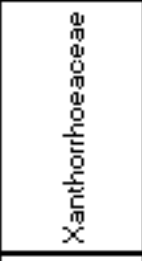 \\
\hline 형 & 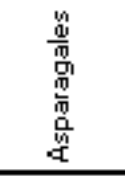 & 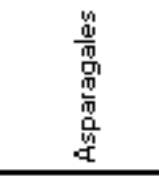 & 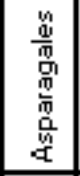 & 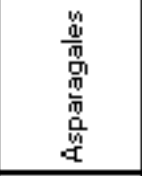 & 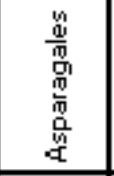 & 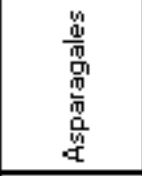 \\
\hline 营 & $\begin{array}{l}\text { 得 } \\
\mathrm{g} \\
\mathrm{g} \\
\mathrm{g} \\
\mathrm{E}\end{array}$ & $\begin{array}{l}\stackrel{y}{0} \\
\stackrel{9}{g} \\
\frac{0}{0} \\
\text { E}\end{array}$ & $\begin{array}{l}\text { y. } \\
\stackrel{0}{0} \\
\mathrm{~g} \\
\text { E }\end{array}$ & $\begin{array}{l}\text { y } \\
\stackrel{9}{g} \\
\stackrel{9}{9} \\
\text { E }\end{array}$ & 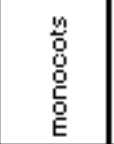 & $\begin{array}{l}\text { y } \\
\stackrel{0}{0} \\
\frac{0}{0} \\
\text { E }\end{array}$ \\
\hline 莒 & $m$ & 5 & $\omega$ & $\stackrel{m}{\risingdotseq}$ & 怘 & $\stackrel{g}{\stackrel{g}{F}}$ \\
\hline
\end{tabular}




\begin{tabular}{|c|c|c|c|c|c|c|c|c|}
\hline 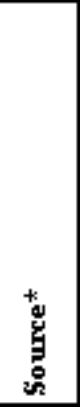 & 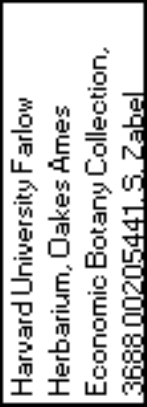 & 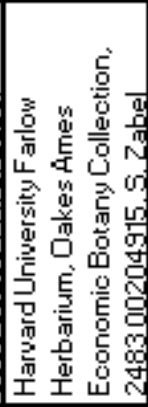 & 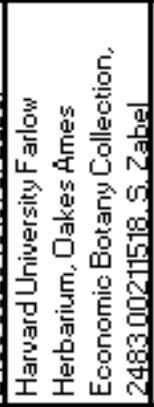 & 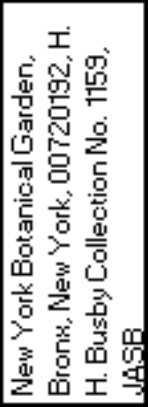 & 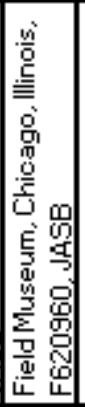 & 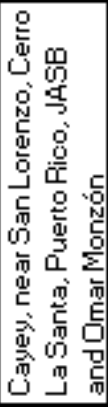 & 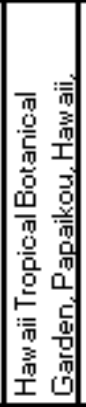 & 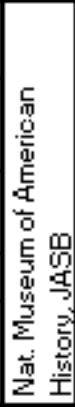 \\
\hline 密 & $\begin{array}{l}\frac{9}{\mathrm{~g}} \\
\frac{\mathrm{g}}{\mathrm{g}} \\
\frac{\mathrm{g}}{\mathrm{a}} \\
\end{array}$ & $\begin{array}{l}\frac{9}{9} \\
\frac{9}{1} \\
\frac{9}{2} \\
\end{array}$ & $\begin{array}{l}\frac{g}{\mathrm{~g}} \\
\frac{9}{\mathrm{~g}} \\
\frac{\mathrm{g}}{\mathrm{a}} \\
\end{array}$ & $\begin{array}{l}\frac{.0}{0} \\
\frac{9}{9} \\
\frac{9}{a} \\
\end{array}$ & $\stackrel{\substack{n\\
}}{\lessgtr}$ & $\begin{array}{l}\text { E } \\
\text { 离 }\end{array}$ & $\begin{array}{l}\text { E } \\
\text { 常 }\end{array}$ & \\
\hline 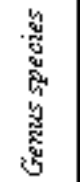 & 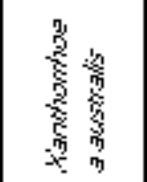 & 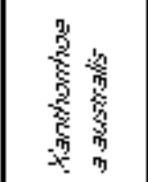 & 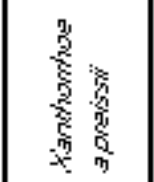 & 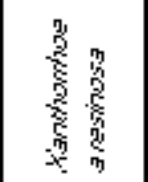 & 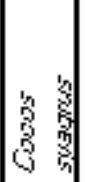 & 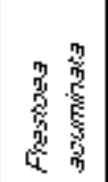 & 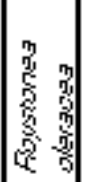 & 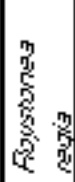 \\
\hline 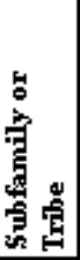 & 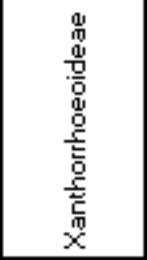 & 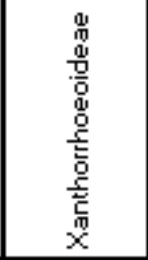 & 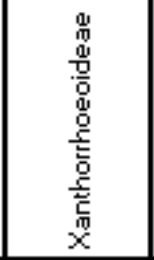 & 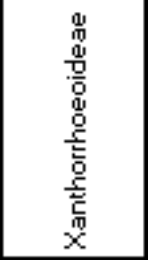 & 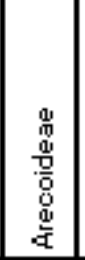 & 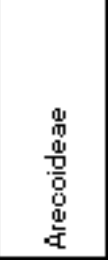 & 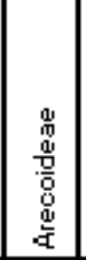 & 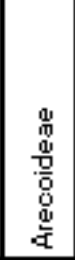 \\
\hline 常 & 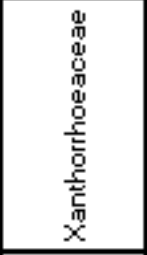 & 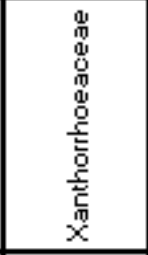 & 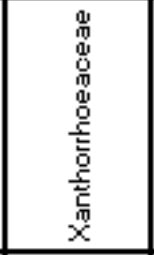 & 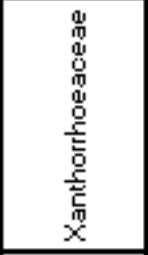 & 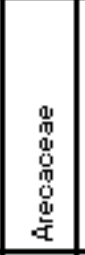 & 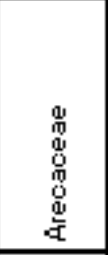 & 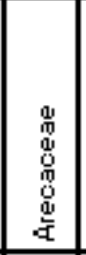 & 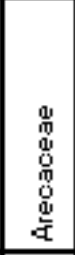 \\
\hline 氧 & 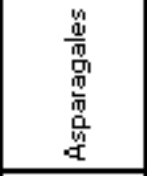 & 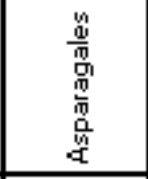 & 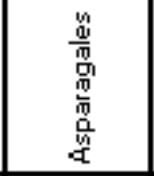 & 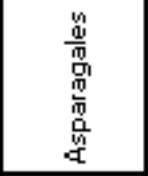 & 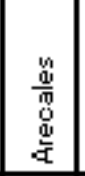 & 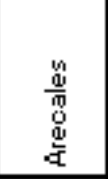 & 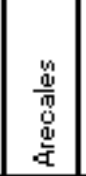 & 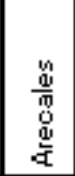 \\
\hline 总 & $\begin{array}{l}\frac{y}{0} \\
\frac{g}{0} \\
\frac{0}{0} \\
\text { E }\end{array}$ & 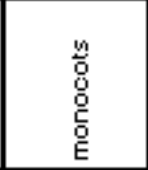 & 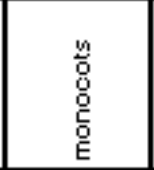 & $\begin{array}{l}\frac{1}{0} \\
\frac{0}{\mathrm{~g}} \\
\mathrm{~g} \\
\mathrm{E}\end{array}$ & 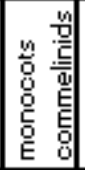 & 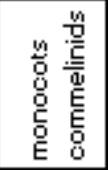 & 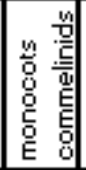 & 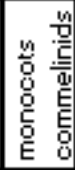 \\
\hline 苜 & $\stackrel{2}{2}$ & 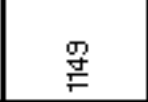 & $\stackrel{m}{\risingdotseq}$ & ष & $\bar{\varnothing}$ & गु & 岕 & $\frac{m}{\%}$ \\
\hline
\end{tabular}




\begin{tabular}{|c|c|c|c|c|c|c|c|c|}
\hline 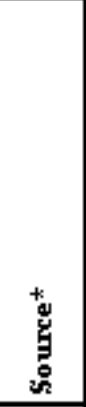 & 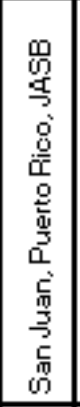 & 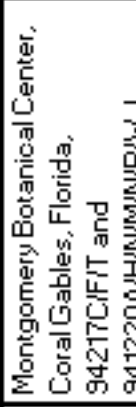 & 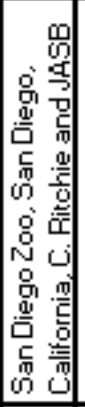 & 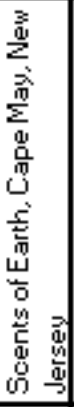 & 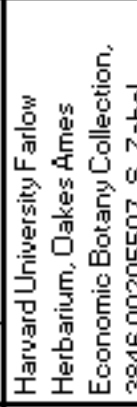 & 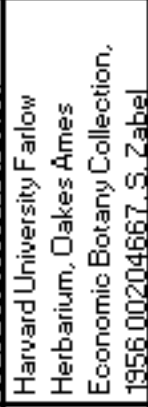 & 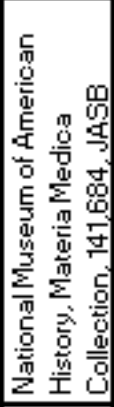 & 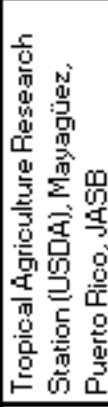 \\
\hline 兽 & $\begin{array}{l}\mathrm{E} \\
\text { 亏े }\end{array}$ & $\begin{array}{l}\mathrm{E} \\
\text { 亏े }\end{array}$ & $\begin{array}{l}\mathrm{E} \\
\text { 光 }\end{array}$ & $\begin{array}{l}\text { 岳 } \\
\text { di }\end{array}$ & $\begin{array}{l}\frac{9}{\bar{g}} \\
\frac{9}{9} \\
\frac{5}{\alpha}\end{array}$ & $\begin{array}{l}\frac{g}{\bar{g}} \\
\frac{\mathrm{g}}{\mathrm{g}} \\
\end{array}$ & $\begin{array}{l}\frac{.0}{0} \\
\frac{0}{5} \\
\frac{a}{5}\end{array}$ & $\begin{array}{l}\text { E } \\
\text { 亏̆ }\end{array}$ \\
\hline 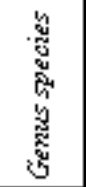 & 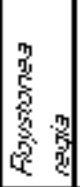 & 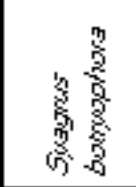 & 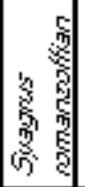 & 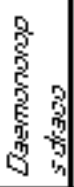 & 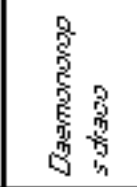 & $\begin{array}{l}\frac{2}{2} \\
\frac{2}{2} \\
\frac{2}{5} \\
\frac{5}{5} \\
\frac{5}{5}\end{array}$ & 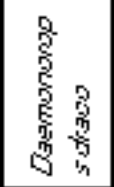 & 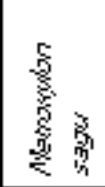 \\
\hline 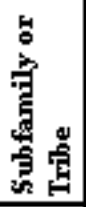 & 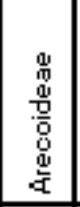 & 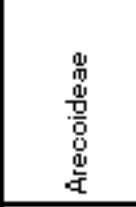 & 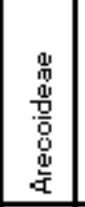 & 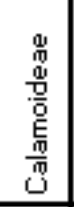 & 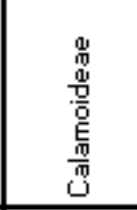 & 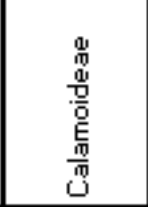 & 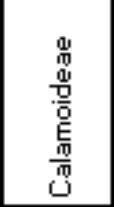 & 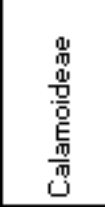 \\
\hline 尝 & 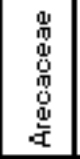 & 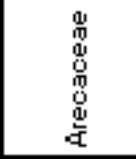 & 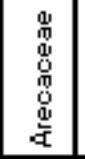 & 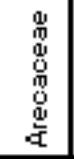 & 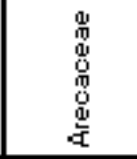 & 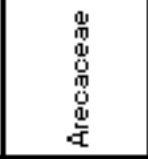 & 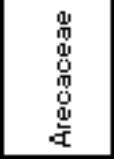 & 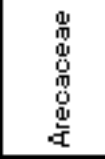 \\
\hline 密 & 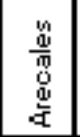 & 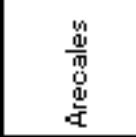 & 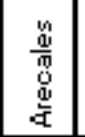 & 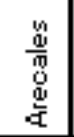 & 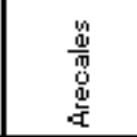 & 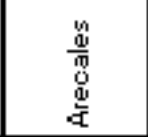 & 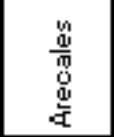 & 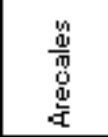 \\
\hline 总 & 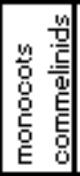 & 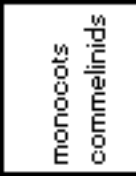 & 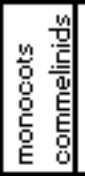 & 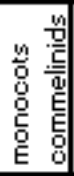 & 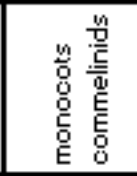 & 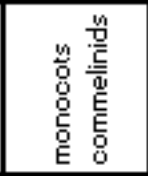 & 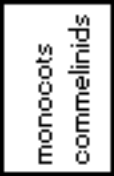 & 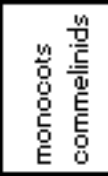 \\
\hline 宾 & 品 & $\bar{m}$ & $\stackrel{\mathrm{m}}{\stackrel{N}{N}}$ & 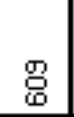 & $F$ & $F$ & $\stackrel{\varrho}{\rightleftharpoons}$ & 耑 \\
\hline
\end{tabular}




\begin{tabular}{|c|c|c|c|c|c|c|c|c|}
\hline 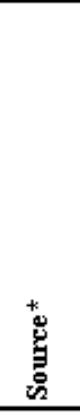 & 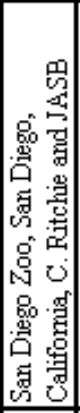 & 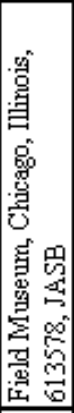 & 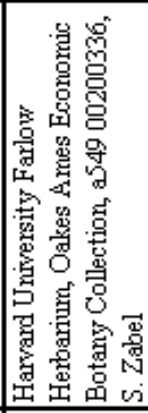 & 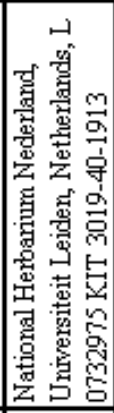 & 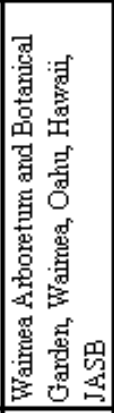 & 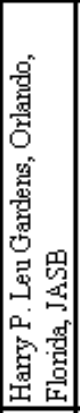 & 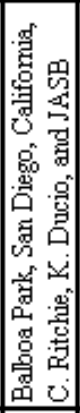 & 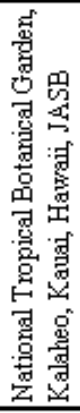 \\
\hline 莺 & $\begin{array}{l}\text { 泀 } \\
\end{array}$ & 恖 & 兽 & $\begin{array}{l}\text { 泀 } \\
\end{array}$ & 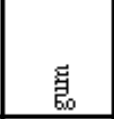 & 葛 & 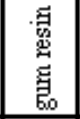 & 泀 \\
\hline 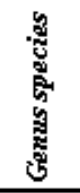 & 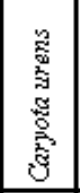 & 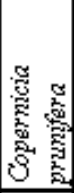 & 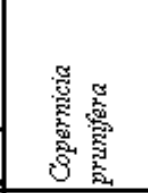 & 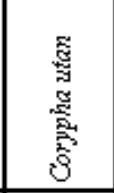 & 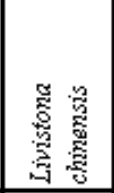 & 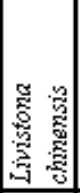 & 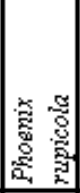 & 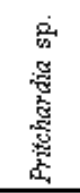 \\
\hline 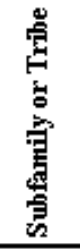 & 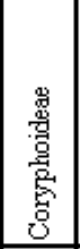 & 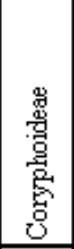 & 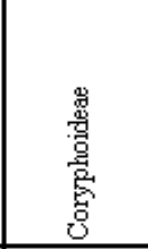 & 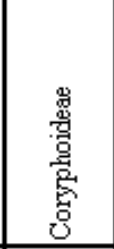 & 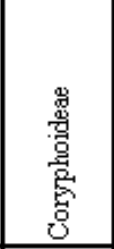 & 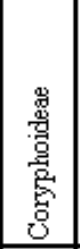 & 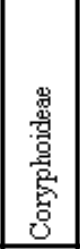 & 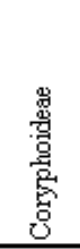 \\
\hline 尝 & 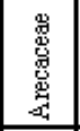 & 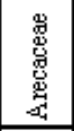 & 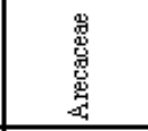 & 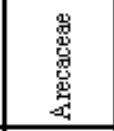 & 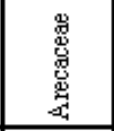 & 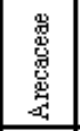 & 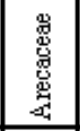 & 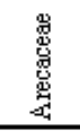 \\
\hline है & 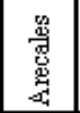 & 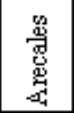 & 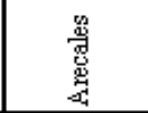 & 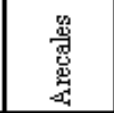 & 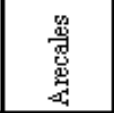 & 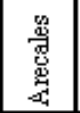 & 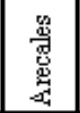 & 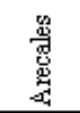 \\
\hline 壱 & 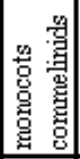 & 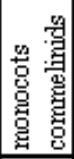 & 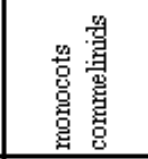 & 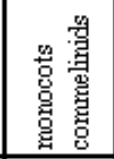 & 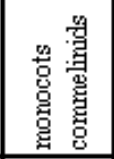 & 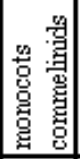 & 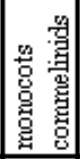 & 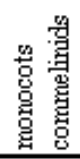 \\
\hline 宫 & $\underset{ح}{\stackrel{ }{コ}}$ & 哭 & $\stackrel{\mathrm{g}}{\mathrm{g}}$ & ఏ & $m$ & $\stackrel{8}{9}$ & $\overrightarrow{\mathrm{d}}$ & 导 \\
\hline
\end{tabular}




\begin{tabular}{|c|c|c|c|c|c|c|c|c|}
\hline 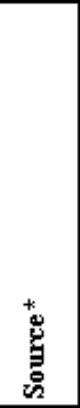 & 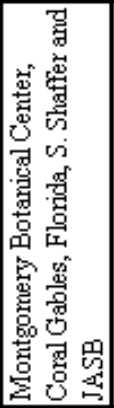 & 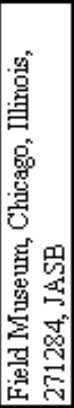 & 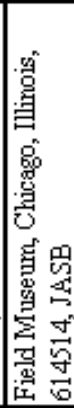 & 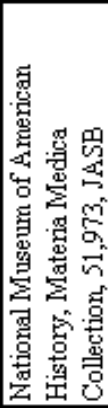 & 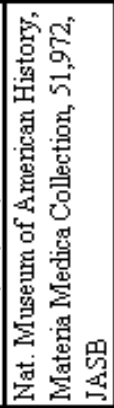 & 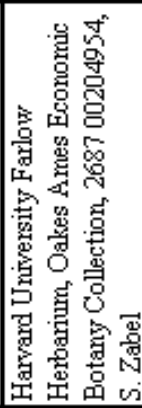 & 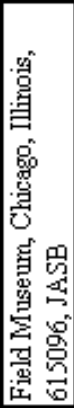 & 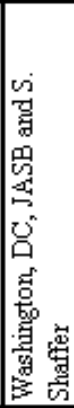 \\
\hline 害泀 & $\begin{array}{l}\text { 茷 } \\
\end{array}$ & 泀 & 总 & $\begin{array}{l}\text { 墨 } \\
\text { 吉 }\end{array}$ & 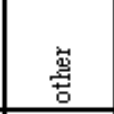 & $\begin{array}{l}\tilde{5} \\
\text { 范 }\end{array}$ & 曾 & $\begin{array}{l}\text { 莗 } \\
\end{array}$ \\
\hline 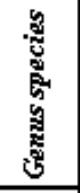 & 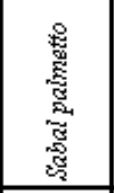 & 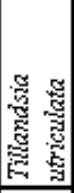 & 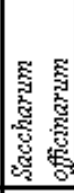 & 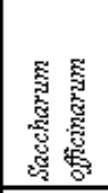 & 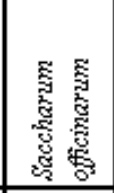 & 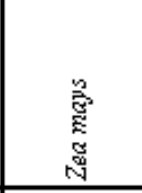 & 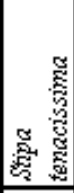 & 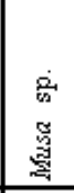 \\
\hline 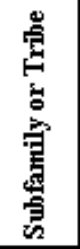 & 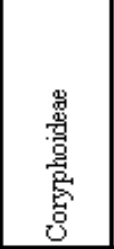 & 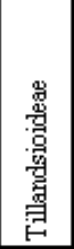 & 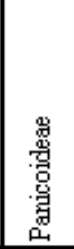 & 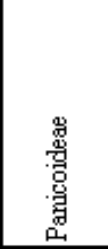 & 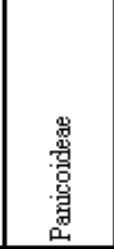 & 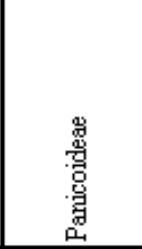 & 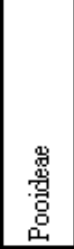 & \\
\hline 苐 & 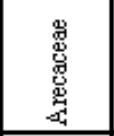 & 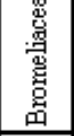 & 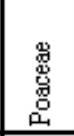 & 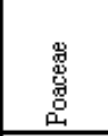 & 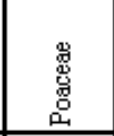 & 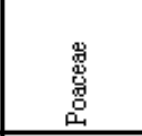 & 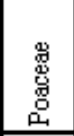 & 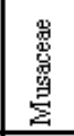 \\
\hline है & 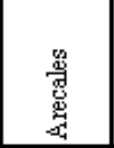 & $\begin{array}{l}\text { 总 } \\
\text { 总 }\end{array}$ & 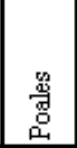 & 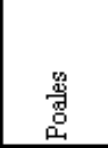 & 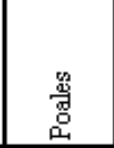 & $\begin{array}{l}\text { 总 } \\
\text { 吕 } \\
\end{array}$ & $\begin{array}{l}\text { 总 } \\
\text { 口 }\end{array}$ & 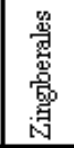 \\
\hline 莺 & 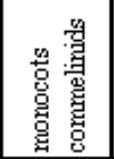 & 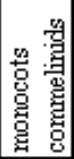 & 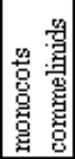 & 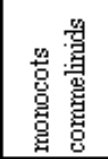 & 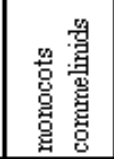 & 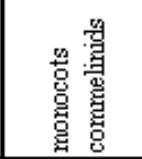 & 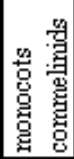 & 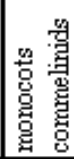 \\
\hline 宮 & $\mathrm{m}$ & $P$ & 悉 & 导 & 守 & $\stackrel{\text { 号 }}{\Xi}$ & 总 & $\stackrel{9}{m}$ \\
\hline
\end{tabular}




\begin{tabular}{|c|c|c|c|c|c|c|c|c|}
\hline * & 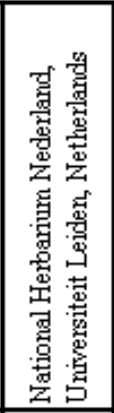 & 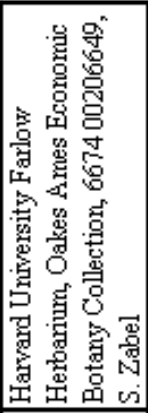 & 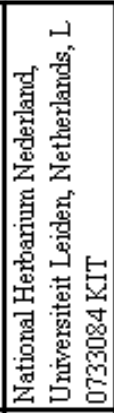 & 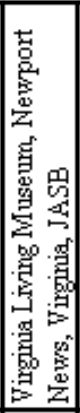 & 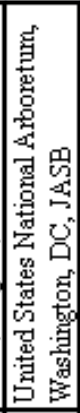 & 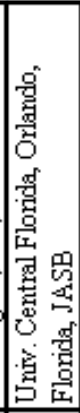 & 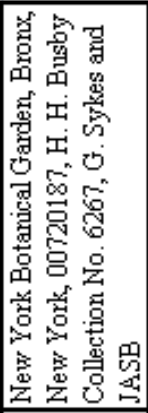 & 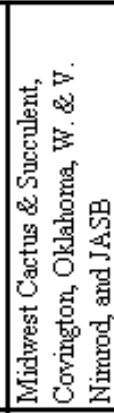 \\
\hline 苞 & 惫 & 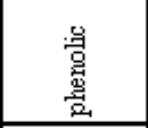 & 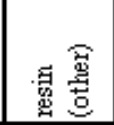 & 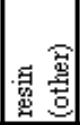 & 急总 & 氞言 & 茞 & $\begin{array}{l}\text { 范 } \\
\text { 苔 } \\
\text { 萬 } \\
\omega_{0}\end{array}$ \\
\hline 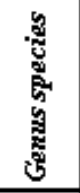 & 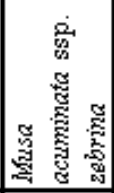 & 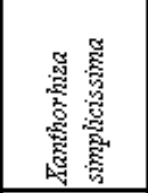 & 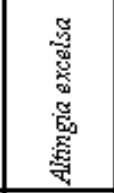 & 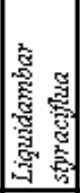 & 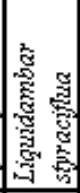 & 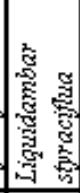 & 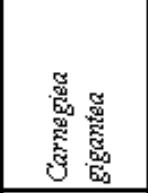 & 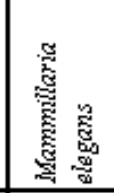 \\
\hline 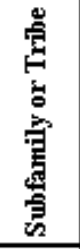 & & & & & & & 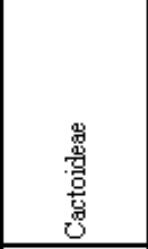 & 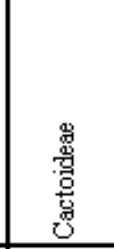 \\
\hline 㓂 & 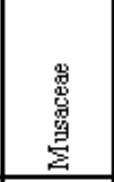 & 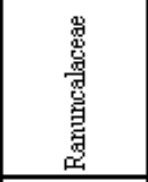 & 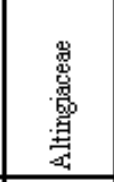 & 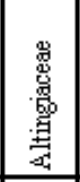 & 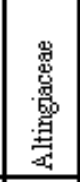 & 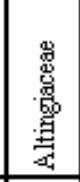 & 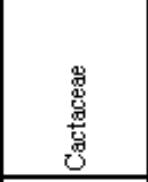 & 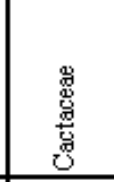 \\
\hline है & 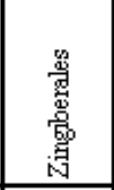 & 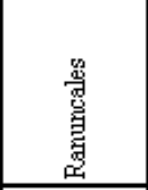 & 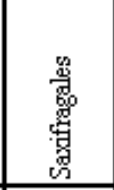 & 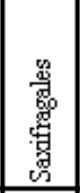 & 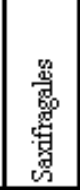 & 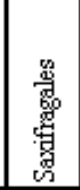 & 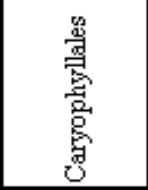 & 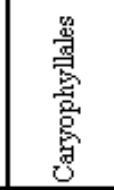 \\
\hline 疍 & 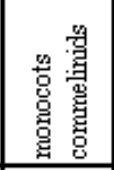 & 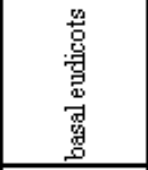 & 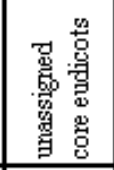 & 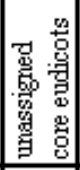 & 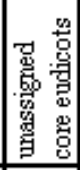 & 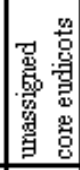 & 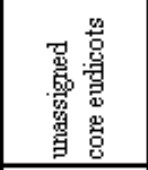 & 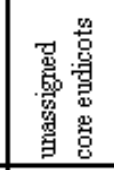 \\
\hline 容 & $\stackrel{\mathrm{g}}{\mathrm{g}}$ & $\stackrel{\Xi}{\Xi}$ & $\underset{\mathrm{\sigma}}{\stackrel{\mathrm{\sigma}}{ }}$ & $m$ & $\%$ & 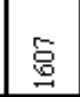 & 迥 & $\infty$ \\
\hline
\end{tabular}




\begin{tabular}{|c|c|c|c|c|c|c|c|c|c|}
\hline 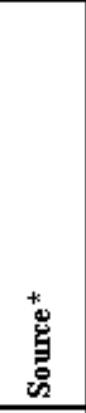 & 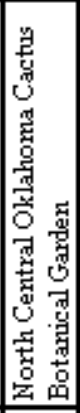 & 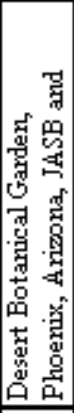 & 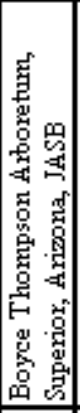 & 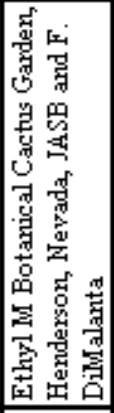 & 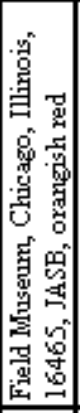 & 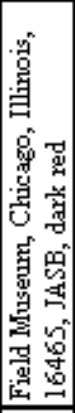 & 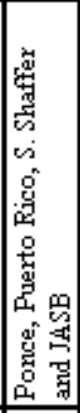 & 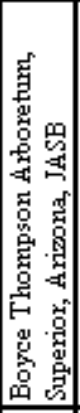 & 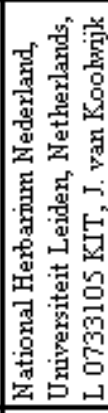 \\
\hline 兽 & 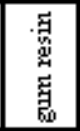 & 苟 & 节 & 范 & 节 & 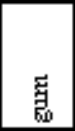 & 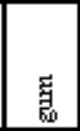 & 铇 & 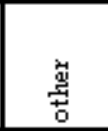 \\
\hline 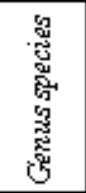 & 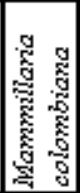 & 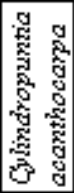 & 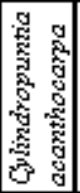 & 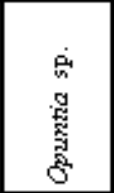 & 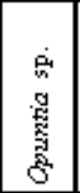 & 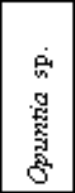 & 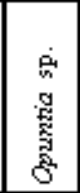 & 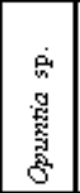 & 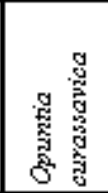 \\
\hline 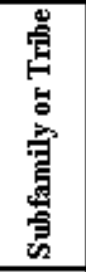 & 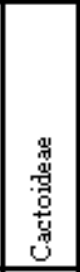 & 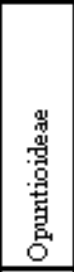 & 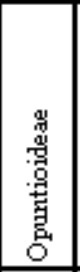 & 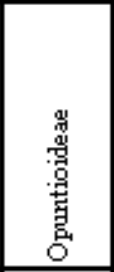 & 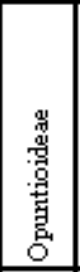 & 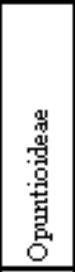 & 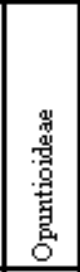 & 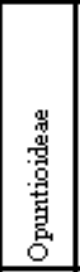 & 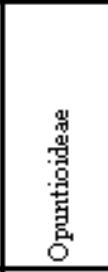 \\
\hline 尝 & 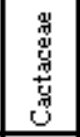 & 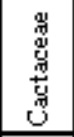 & 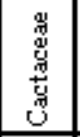 & 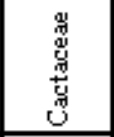 & 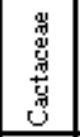 & 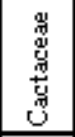 & 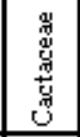 & 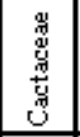 & 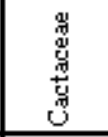 \\
\hline 䓌 & 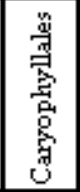 & 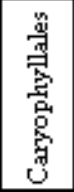 & 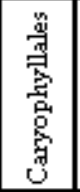 & 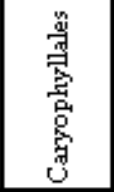 & 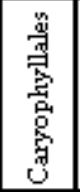 & 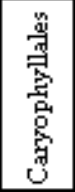 & 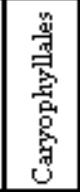 & 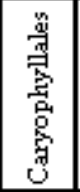 & 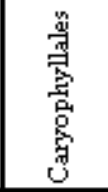 \\
\hline 咆 & 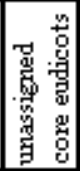 & 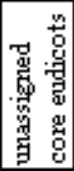 & 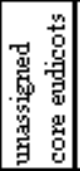 & 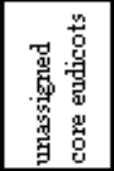 & 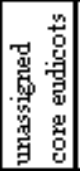 & 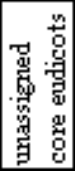 & 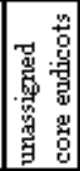 & 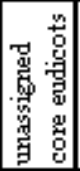 & 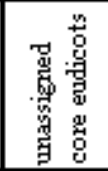 \\
\hline 总 & 导 & 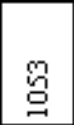 & 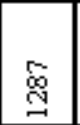 & y & $\curvearrowleft$ & $n$ & $\overrightarrow{6}$ & $\stackrel{9}{9}$ & త্ণ \\
\hline
\end{tabular}




\begin{tabular}{|c|c|c|c|c|c|c|}
\hline 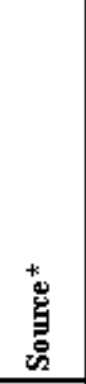 & 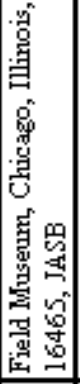 & 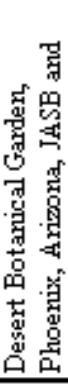 & 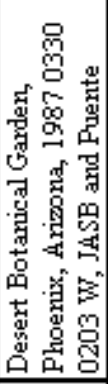 & 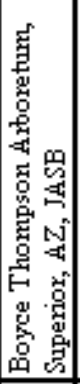 & 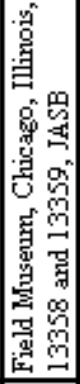 & 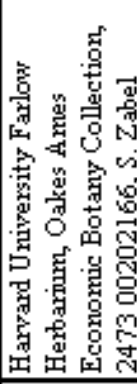 \\
\hline 兽 & 节 & 节 & 节 & 节 & 节 & 节 \\
\hline 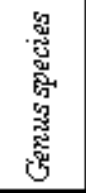 & 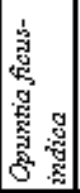 & 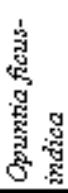 & 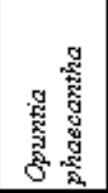 & 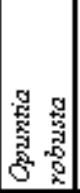 & 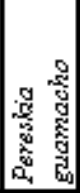 & 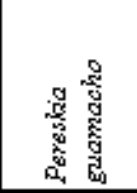 \\
\hline 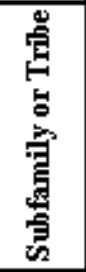 & 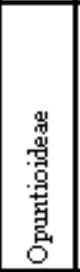 & 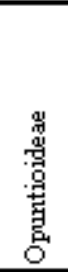 & 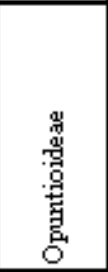 & 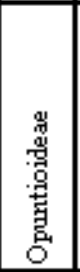 & 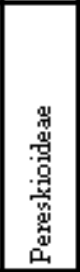 & 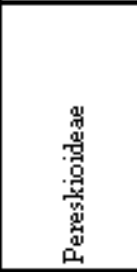 \\
\hline 点 & 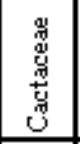 & 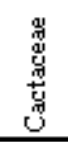 & 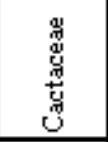 & 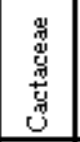 & 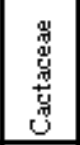 & 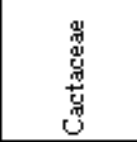 \\
\hline 预 & 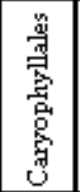 & 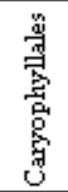 & 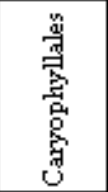 & 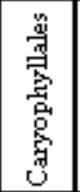 & 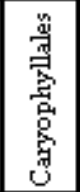 & 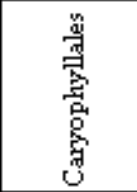 \\
\hline 氶 & 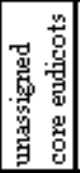 & 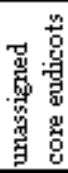 & 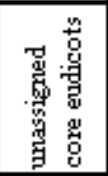 & 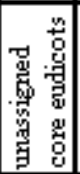 & 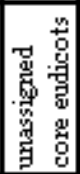 & 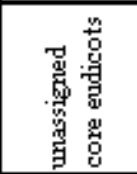 \\
\hline 㻤 & $m$ & 恣 & 응 & 总 & $n$ & 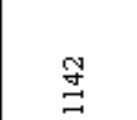 \\
\hline
\end{tabular}

